\title{
Modelling of Multiphase Flow in a Blast Furnace: Recent Developments and Future Work
}

\author{
Xuefeng DONG, ${ }^{11}$ Aibing YU, ${ }^{1)}$ Jun-ichiro YAGI ${ }^{11}$ and Paul ZULLI ${ }^{21}$ \\ 1) Center for Simulation and Modelling of Particulate Systems, School of Materials Science and Engineering, The University of \\ New South Wales, Sydney, NSW 2052, Australia. E-mail: a.yu@unsw.edu.au \\ 2) Bluescope Steel Research, P. O. Box \\ 202, Port Kembla, NSW 2505, Australia.
}

(Received on January 4, 2007; accepted on August 23, 2007)

\begin{abstract}
An ironmaking blast furnace is a complex multiphase flow reactor involving gas, powder, liquid and solid phases. Understanding the flow behaviour of these phases is of paramount importance to the control and optimization of the process. Mathematical modelling, often coupled with physical modelling, plays an important role in this development. Yagi ${ }^{1)}$ gave a comprehensive review of the early studies in this area in 1993. Significant progress has since been made, partially driven by the needs in research but mainly as a result of the rapid development of computer and computational technologies. This paper reviews these developments, covering the formulation, validation and application of mathematical models for gas-solid, gas-liquid, gas-powder and multiphase flows. The need for further developments is also discussed.
\end{abstract}

KEY WORDS: ironmaking; blast furnace; multiphase flow; two fluid model; discrete element method.

\section{Introduction}

Blast furnace (BF) ironmaking is an important technology by which iron is efficiently reduced from iron-bearing materials. $^{2)}$ In this process, coke and ore particles are charged, layer by layer using either a bell or bell-less top, and descend through the BF under gravity. During the descent, ore is reduced and then melts in the cohesive zone forming liquid (slag, iron), which flows into the hearth. Coke is partially gasified before flowing into the raceway, where it combusts with hot blast (oxygen-enriched air) to form reducing gas and process heat. These reducing gases flow countercurrently through the particle bed. If pulverized coal injection (PCI) is practiced at high rates, unburnt coal as a powder phase may leave the raceway region through gas entrainment. The BF process is therefore very complex involving multiple phases (gases, granular solids, liquids, and powders) which undergo various chemical and physical phenomena.

Understanding the in-furnace behaviour of these phases is a necessary prerequisite to developing appropriate strategies for long term BF operations. It is very difficult to measure directly the internal flows in a BF because of the high temperature and hazardous conditions. Consequently, mathematical modelling, often coupled with physical modelling, has played an important role in this development. Yagi ${ }^{1)}$ gave a comprehensive review of the early studies in this area in 1993. The review summarized the formulation of continuum models for four fluid flow, extended from the previous models for single-, two- and three-phase flows. With appropriate setting of the initial and boundary conditions, some of these models demonstrated the ability to de- scribe the macroscopic flow behaviour including, e.g., the solid flow in the BF shaft, ${ }^{3-6)}$ the dilute powder flow ${ }^{7-12)}$ and liquid flow ${ }^{4,13-15)}$ in a simplified BF. It also demonstrated the limitation of the models in describing the strong localized flow in regions such as raceway and cohesive zone and in extracting microscopic information to establish constitutive relations for solid flow and interactions between some phases, e.g. liquid and powder. In the past decade or so, significant progress has been made to overcome these deficiencies, mainly as a result of the rapid development of computer and computational technologies. For example, mathematical models have been developed to describe the localized flow of liquids in the cohesive zone and deadman, ${ }^{16,17)}$ solid flow in the raceway and down to the furnace hearth, ${ }^{18-22)}$ abnormal flows such as burden hanging, ${ }^{23)}$ powder flow and accumulation, ${ }^{24)}$ and liquid flooding. ${ }^{25)}$ Process modelling has also been developed rapidly: now the $\mathrm{BF}$ ironmaking can be modelled as a three-dimensional transient process. ${ }^{26)}$ Some progress recently made in this direction has been discussed by Takatani ${ }^{27)}$ and Nogami. ${ }^{28)}$

This paper reviews these developments, with reference to the formulation, validation and application of the mathematical models newly proposed. In Sec. 2, the model framework is first discussed in connection with the new developments in particulate and multiphase flow. Then the modelling of gas-solid, gas-powder, and gas-liquid flows is discussed in Secs. 3-5, where emphasis is given to new modelling techniques and new findings related to the flow in different zones in a BF. The combination of these twofluid flow models for the modelling of multiphase flow and BF process as a whole is discussed in Secs. 6 and 7. Section 8 provides a summary and discusses the areas for further 
development.

\section{Mathematical Modelling}

Generally speaking, the existing approaches to modelling the multiphase flow in a BF can be classified into two categories: continuum approach at a macroscopic level and discrete approach at a microscopic level. In the continuum approach, phases are generally considered as fully interpenetrating continuum media and described by separate conservation equations with appropriate constitutive relations and interaction terms representing the coupling between phases. The general governing equations are based on the so-called two fluid model (TFM), originally developed for gas-particle flow, ${ }^{29-31)}$ given by:

Conservation of mass

$$
\frac{\partial}{\partial t}\left(\varepsilon_{i} \rho_{i}\right)+\nabla \cdot\left(\varepsilon_{i} \rho_{i} \mathbf{u}_{i}\right)=S_{i}
$$

Conservation of momentum

$$
\begin{aligned}
\operatorname{Model} A \frac{\partial}{\partial t}\left(\varepsilon_{i} \rho_{i} \mathbf{u}_{i}\right)+\nabla \cdot\left(\varepsilon_{i} \rho_{i} \mathbf{u}_{i} \mathbf{u}_{i}\right) \\
=-\varepsilon_{i} \nabla p+\nabla \cdot \boldsymbol{\tau}_{i}+\sum_{j}\left(\mathbf{F}_{i}^{j}\right)^{A}+\varepsilon_{i} \rho_{i} \mathbf{g}
\end{aligned}
$$

or

$$
\begin{aligned}
& \text { Model B } \frac{\partial}{\partial t}\left(\varepsilon_{i} \rho_{i} \mathbf{u}_{i}\right)+\nabla \cdot\left(\varepsilon_{i} \rho_{i} \mathbf{u}_{i} \mathbf{u}_{i}\right) \\
& \quad=-\nabla p+\nabla \cdot \boldsymbol{\tau}_{i}+\sum_{j}\left(\mathbf{F}_{i}^{j}\right)^{B}+\varepsilon_{i} \rho_{i} \mathbf{g}
\end{aligned}
$$

The so-called Model A and Model B result from the treatment of the fluid pressure. For example, for gas-solid flow, Model A assumes the pressure is shared between the two phases, while in Model B, the pressure is attributed to gas phase only. ${ }^{31)}$ Model A formulation has been widely used in multiphase modelling, especially in process metallurgy. Model B formulation was recently used in the so called combined continuum and discrete method for coupled flow of continuum fluid and discrete particles. ${ }^{32}$ )

The continuum approach is suitable for process modelling and applied research because of its computational convenience and efficiency. Indeed, most of the BF modelling is based on this approach. However, its effective use heavily depends on constitutive or closure relations and the momentum exchange between phases. For Newtonian fluids (gas and liquid here), these relations can be readily determined. For non-Newtonian fluids such as solids and powder, general theories are not yet available. In the past, various theories have been devised for different flow regimes (three flow regimes have been identified: quasi-static regime, rapid flow regime and a transitional regime that lies inbetween). For example, models have been proposed to derive the constitutive equations for the rate-independent deformation of granular materials based on either the plasticity theory or the double shearing theory; the rapid flow of granular materials has been described by extending the kinetic theory of dense gases; the transitional regime that involves both collisional and frictional mechanisms is studied by use of the kinetic theory combined with the MohrCoulomb quasi-static theory. ${ }^{31,33,34)}$

The momentum exchange between phases, $\mathbf{F}_{i}^{j}$, is also critical. Table 1 lists the correlations formulated in the framework of Model A and being used in BF modelling to some degree of success. However, it should be pointed out that to date, there is still no accepted continuum theory for the establishment of constitutive equations and consistent opinions for closure relations applicable to particulate and multiphase flow. This is particularly true for solid and powder particles. Moreover, particles of different size/type

\begin{tabular}{|c|c|c|}
\hline & Interaction forces & References \\
\hline G-S & $\mathbf{F}_{g}^{s}=-\mathbf{F}_{s}^{g}=-\left[150 \mu_{g} \frac{a_{g s}^{2}}{36 \varepsilon_{g}}+1.75 \rho_{g} a_{g s}\left|\mathbf{u}_{g}-\mathbf{u}_{s}\right|\right]\left(\mathbf{u}_{g}-\mathbf{u}_{s}\right)$ & $1,34-38$ \\
\hline \multirow[b]{2}{*}{ G-L } & $\mathbf{F}_{g}^{l}=-\mathbf{F}_{l}^{g}=-0.75 C_{d, g l} \frac{\varepsilon_{l} \rho_{g}}{\phi_{l} d_{l}}\left|\mathbf{u}_{g}-\mathbf{u}_{l}\right|\left(\mathbf{u}_{g}-\mathbf{u}_{l}\right)$ & $1,4,14,15,38$ \\
\hline & $\mathbf{F}_{g}^{l}=-\mathbf{F}_{l}^{g}=-\left[150 f_{g l, 1} \frac{(1-\varepsilon)^{2} \mu_{g}}{d_{s}^{2} \varepsilon_{g}}+1.75 f_{g l, 2} \frac{(1-\varepsilon) \rho_{g}}{d_{s}}\left|\mathbf{u}_{g}-\mathbf{u}_{l}\right|\right]\left(\mathbf{u}_{g}-\mathbf{u}_{l}\right)$ & 39 \\
\hline G-F & $\mathbf{F}_{g}^{f}=-\mathbf{F}_{f}^{g}=-0.75 C_{d, g f} \frac{\varepsilon_{f} \rho_{g}}{\phi_{f} d_{f}}\left|\mathbf{u}_{g}-\mathbf{u}_{f}\right|\left(\mathbf{u}_{g}-\mathbf{u}_{f}\right)$ & $12,38,40-42$ \\
\hline \multirow[b]{2}{*}{$\mathrm{F}-\mathrm{S}$} & $\mathbf{F}_{f}^{s}=-\mathbf{F}_{s}^{f}=-\frac{1}{2 \mathrm{D}^{*}} C_{d, f s} \rho_{\mathrm{f}} \varepsilon_{\mathrm{f}}\left|\mathbf{u}_{\mathrm{f}}-\mathbf{u}_{\mathrm{s}}\right|\left(\mathbf{u}_{\mathrm{f}}-\mathbf{u}_{\mathrm{s}}\right)$ & $12,38,40,41$ \\
\hline & $\mathbf{F}_{f}^{s}=-\mathbf{F}_{s}^{f}=-\frac{3}{2} \frac{1+e_{f s}}{1-e_{f s}} \frac{\left(1-\varepsilon_{f}\right) \rho_{f}\left(1-\varepsilon_{s}\right) \rho_{s}\left(d_{f}+d_{s}\right)^{2}}{\rho_{f} d_{f}^{3}+\rho_{s} d_{s}^{3}}\left|\mathbf{u}_{f}\right| \mathbf{u}_{f}$ & 23 \\
\hline \multirow[b]{2}{*}{ L-S } & $\mathbf{F}_{l}^{s}=-\mathbf{F}_{s}^{l}=-C_{d, l s} \mu_{l}\left|\mathbf{u}_{1}-\mathbf{u}_{\mathrm{s}}\right|\left(\mathbf{u}_{1}-\mathbf{u}_{\mathrm{s}}\right)$ & $1,4,14,38$ \\
\hline & $\mathbf{F}_{l}^{s}=-\mathbf{F}_{s}^{l}=-\left[150 f_{l s, 1} \frac{(1-\varepsilon)^{2} \mu_{l}}{d_{s}^{2} \varepsilon_{l}}+1.75 f_{l s, 2} \frac{(1-\varepsilon) \rho_{l}}{d_{l}}\left|\mathbf{u}_{l}-\mathbf{u}_{s}\right|\right]\left(\mathbf{u}_{l}-\mathbf{u}_{s}\right)$ & 39 \\
\hline L-F & $\mathbf{F}_{l}^{f}=-\mathbf{F}_{f}^{l}=-f_{l f} \operatorname{Re}_{l}^{0.798} \mathrm{Fr}_{s}^{-1.966} \mathrm{Fr}_{f}^{1.096} \operatorname{Re}_{g}^{4.31}\left(\mathbf{u}_{l}-\mathbf{u}_{f}\right) /\left|\mathbf{u}_{l}-\mathbf{u}_{f}\right|$ & 43 \\
\hline
\end{tabular}
should be treated as different phases in order to describe size or density segregation. However, no such continuum modelling has been attempted for the solid flow in a BF yet.

Table 1. Empirical correlations for the interaction forces between phases. 
In the discrete approach, phases are described based on the analysis of the motion of individual fluid elements which are atoms for gas or liquid, and particles for solid. So the approach can simulate fluid flow at an atomic or particle scale, and has the advantage that there is no need for complex constitutive relations between the stress and strain tensors under different flow conditions. It can generate microscopic information such as the trajectory of, and forces acting on, individual atoms or particles, which is important to understand the fundamentals. However, computationally it is extremely demanding. For this reason, it is not possible for gas and liquid phases in any practical system which is better handled by the continuum approach as mentioned above. To date, the discrete approach has only been applied to solid phase.

A foremost discrete approach is the so-called discrete element method (DEM). ${ }^{44)}$ In DEM, Newton's law of motion describes the translational and rotational motions of a particle in a particulate system:

$$
\begin{aligned}
& m_{i} \frac{d \mathbf{v}_{i}}{d t}=\sum_{j=1}^{k_{i}}\left(\mathbf{f}_{c, i j}+\mathbf{f}_{d, i j}\right)+\mathbf{f}_{f l, i}+m_{i} \mathbf{g} \\
& I_{i} \frac{d \boldsymbol{\omega}_{i}}{d t}=\sum_{j=1}^{k_{i}}\left(\mathbf{T}_{t, i j}+\mathbf{T}_{r, i j}\right)
\end{aligned}
$$

The forces and torques considered include gravity and those originating from the particle's interactions with neighbouring particles, walls and surrounding fluids. These interactions include the inter-particle forces due to collision between particles (contact force and viscous contact damping force $)^{45-47)}$ or other effects (van der Waals force and electrostatic force associated with fine particles, capillary and viscous forces associated with wet particles, and solidbonding forces). ${ }^{48,49)}$ Particle-fluid interactions include buoyancy, ${ }^{22,50)}$ drag force, ${ }^{18,51)}$ lift force, ${ }^{52,53)}$ virtual mass force $^{54-56)}$ and Basset force. ${ }^{54,55)}$ These forces have been implemented in different particle systems by various investigators. To date, equations required to describe some of the forces are not fully determined. Hence, the development of a more comprehensive theory and associated experimental techniques to quantify the interaction forces between particles and between particle and fluid under various conditions will remain an active research area. As an example, Table 2 lists the equations employed by $\mathrm{Yu}$ and colleagues ${ }^{19,47,48,50,51,57)}$ to calculate the forces and torques.

When applied to particle-fluid flow, DEM needs to be coupled with Computational Fluid Dynamics (CFD) that describes the flow of fluids such as gas and/or liquid based on the Navier-Stokes equations, giving the so-called DEMCFD or combined continuum and discrete model (CCDM). ${ }^{51,58,59)}$ In principle, the coupling between the continuum fluid and discrete particles can be made at different time and length scales. The most popular one is that the motion of individual particles is obtained by solving Newton's second law of motion, given by Eqs. (3) and (4), and fluid flow by the Navier-Stokes equation based on the concept of local average, given by Eqs. (1) and (2). Their coupling can be made as follows. ${ }^{51)}$ At each time step, DEM provides information, such as the positions and velocities of individual particles, for the evaluation of porosity and volumetric fluid drag force in a computational cell. CFD will then use these data to determine the fluid flow fieldwhich then yields the fluid drag forces acting on individual particles. Incorporation of the resulting forces into DEM will produce information about the motion of individual particles for the next time step. CCDM has been widely used in the study of gas fluidization. However, it has also been used in the recent study of gas-solid flow in a $\mathrm{BF}^{18-21,60)}$

\section{Gas-Solid Flow}

In relation to the bulk flow of solid (or burden) in the blast furnace, there are several areas of direct practical significance, including burden descent in the shaft and active zone, coke motion within and around the raceway region, and deadman behaviour in the hearth. For example, the de-

\begin{tabular}{|c|c|c|}
\hline Forces and torques & Symbols & Equations \\
\hline Normal elastic force & $\mathbf{f}_{c n, i j}$ & $-\frac{4}{3} E^{*} \sqrt{R^{*}} \delta_{n}^{3 / 2} \mathbf{n}$ \\
\hline Normal damping force & $\mathbf{f}_{d n, i j}$ & $-c_{n}\left(8 m_{i j} E^{*} \sqrt{R^{*} \delta_{n}}\right)^{1 / 2} \mathbf{v}_{n, i j}$ \\
\hline Tangential elastic force & $\mathbf{f}_{c t, i j}$ & $-\mu_{s f}\left|\mathbf{f}_{c n, i j}\right|\left(1-\left(1-\delta_{t} / \delta_{t, \max }\right)^{3 / 2}\right) \hat{\boldsymbol{\delta}}_{t} \quad\left(\delta_{t}<\delta_{t, \max }\right)$ \\
\hline Tangential damping force & $\mathbf{f}_{d t, i j}$ & $\begin{array}{l}-c_{t}\left(6 \mu_{s f} m_{i j}\left|\mathbf{f}_{c n, i j}\right| \sqrt{1-\left|\mathbf{v}_{t, i j}\right| / \delta_{t, \max }} / \delta_{t, \max }\right)^{1 / 2} \mathbf{v}_{t, i j} \\
\left(\delta_{t}<\delta_{t, \max }\right)\end{array}$ \\
\hline Coulomb friction force & $\mathbf{f}_{t, i j}$ & $-\mu_{s f}\left|\mathbf{f}_{c n, i j}\right| \hat{\boldsymbol{\delta}}_{t}$ \\
\hline Fluid drag force & $\mathbf{f}_{f l, i}$ & $0.5 c_{d o, i} \rho_{f l} \pi R_{i}^{2} \varepsilon_{i}^{2}\left|\boldsymbol{u}_{i}-\boldsymbol{v}_{i}\right|\left(\boldsymbol{u}_{i}-\boldsymbol{v}_{i}\right) \varepsilon_{i}^{-(\chi+1)}$ \\
\hline Torque & $\mathbf{T}_{t, i j}$ & $\mathbf{R}_{i j} \times\left(\mathbf{f}_{c t, i j}+\mathbf{f}_{d t, i j}\right)$ \\
\hline Rolling friction torque & $\mathbf{T}_{n, i j}$ & $\mu_{r, i j}\left|\mathbf{f}_{n, i j}\right| \widehat{\boldsymbol{\omega}}_{t, i j}^{n}$ \\
\hline where $\frac{1}{R^{*}}=\frac{1}{\left|\mathbf{R}_{i}\right|}+\frac{1}{\left|\mathbf{R}_{j}\right|}$ & $E^{*}=\frac{E}{2\left(1-v^{2}\right)}$ & $\quad \hat{\boldsymbol{\omega}}_{t, i j}=\frac{\boldsymbol{\omega}_{t, i j}}{\left|\boldsymbol{\omega}_{t, i j}\right|}, \quad \hat{\boldsymbol{\delta}}_{t}=\frac{\boldsymbol{\delta}_{t}}{\left|\boldsymbol{\delta}_{t}\right|}, \delta_{t, \max }=\mu_{s f} \frac{2-v}{2(1-v)} \delta_{n}$ \\
\hline \multicolumn{3}{|c|}{$\begin{array}{l}\mathbf{v}_{i j}=\mathbf{v}_{j}-\mathbf{v}_{i}+\boldsymbol{\omega}_{j} \times \mathbf{R}_{j}-\boldsymbol{\omega}_{i} \times \mathbf{R}_{i}, \mathbf{v}_{n, i j}=\left(\mathbf{v}_{i j} \cdot \mathbf{n}\right) \cdot \mathbf{n}, \mathbf{v}_{t, i j}=\left(\mathbf{v}_{i j} \times \mathbf{n}\right) \times \mathbf{n} . \text { Note that tangential forces }\left(\mathbf{f}_{c t, i j}+\mathbf{f}_{d t, i j}\right) \\
\text { should be replaced by } \mathbf{f}_{t, i j} \text { when } \delta_{t} \geq \delta_{t, \max } .\end{array}$} \\
\hline
\end{tabular}

Table 2. Components of forces and torques acting on particle $i$. 
scending rate of burden, ore/coke distribution in the upper region and packing state of coke in the lower zone determine, to a large extent, the stability of BF operation. In the following, major research outcomes in the past decade or so are briefly discussed with respect to these regions: shaft, raceway and hearth.

\subsection{BF Shaft}

The movement of burden in the BF shaft covers both the formation process or burden distribution and the solid flow which is driven mainly by the combustion of coke at the tuyeres and the conversion of iron ore to liquid in the cohesive zone. Four flow regions have been identified in the BF shaft ${ }^{6,61,62)}$ : plug flow at the top part where uniform velocity occurs; stagnant zone (deadman) in the center of the lower part where particles are often regarded as static; quasi-stagnant zone, adjacent to the deadman, where particles move very slowly; and converging flow region where particles have a significant velocity variation between the furnace wall and stagnant zone. There have been numerous physical modelling studies undertaken on burden distribution, ${ }^{63-66)}$ solid flow pattern ${ }^{6,61,62,67)}$ and stress state. ${ }^{68)}$ These studies have both improved our understanding of the macroscopic features of solid flow and provided data with which to validate numerical models. The results for BF solid flow are however largely of a macroscopic nature and are not enough for establishing a comprehensive picture about the flow system. In fact, characteristics and microstructure at a particle scale for this particulate system are difficult to obtain even with well-controlled physical models. In recent years, mathematical modelling has become a powerful tool to study solid (granular) flow, with two approaches being adopted: discrete and continuum as described above. The continuum approach dominated numerical simulation of solid flow before the early 1990s. ${ }^{1,4,37)}$ Over the past ten years, with advancement in computer technology and numerical algorithm, the discrete approach is increasingly being adopted.

\subsubsection{Continuum Model}

By extending the principle of fluid mechanics, several continuum models have been proposed to describe solid flow. These models include the plug flow, ${ }^{3)}$ potential flow, ${ }^{4}$ kinematic $^{5)}$ and viscous flow model. ${ }^{37)}$ In contrast to the other three models, the viscous flow model generates results more comparable to those measured. ${ }^{37)}$ It treats solid particles as a high viscous fluid that can be described by the well established Newtonian constitutive equations. However, the original model had limited applicability because it required the profile of stagnant zone to be known a priori. Therefore, this model has undergone some developments in the recent studies.

On the basis of fluid and solid mechanics principles, a new mathematical model has been developed. ${ }^{34)}$ In this model, the concept of viscosity is used to represent the hydrodynamic particle-particle interaction (rate dependent part), and the concept of a solid plastic modulus and Coulomb frictional relation are employed to describe the frictional contact interaction (rate independent part). The surface stress for solid phase, $\tau_{i}$, consists of two parts: 1) Newtonian type of constitutive equation, i.e. $\tau_{r d}=2 \varepsilon_{s} \mu_{s} \mathbf{D}_{s}$

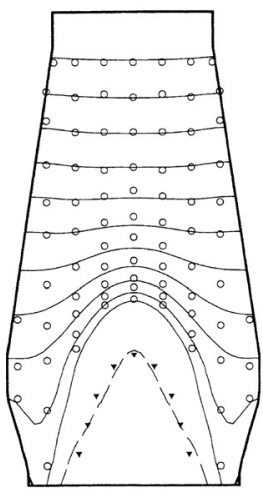

(a)

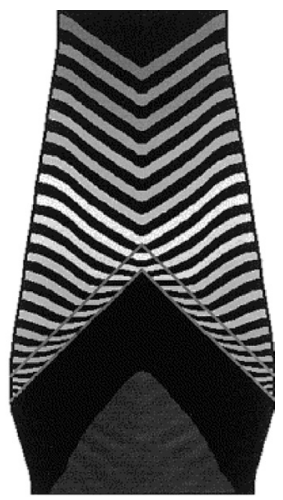

(b)
Fig. 1. (a) Calculated (lines) and measured (points) solid timelines and stagnant zone profile ${ }^{34)}$; and (b) evolution of ore and coke layer profiles within the furnace based on a predetermined cohesive zone shape. ${ }^{69)}$

$-2 / 3 \varepsilon_{s} \mu_{s} t r \mathbf{D}_{s} \mathbf{I}$ and 2) particle-particle contact interaction due to packing, including normal contact and shear friction, i.e. $\boldsymbol{\tau}_{r i}=-P_{e} \mathbf{I}+2 \eta_{s} \mathbf{D}_{s} / \sqrt{\operatorname{tr} \mathbf{D}_{s}^{2}}$. A solution procedure is established to determine the transition or boundary between the moving and non-moving zones, i.e. the profile of stagnant zone.

Figure 1(a) shows the calculated and measured residence time profiles for the solid flow in a BF geometry. The model predictions are in good agreement with the experimental measurements. Three flow regions can be identified: plug flow in the upper part, converged flow in the lower part and very slow flow in the region between stagnant and flow zones. The model is also extended to investigate the effects of layered burden and solid consumption on the solid flow. ${ }^{69)}$ Figure 1(b) shows the calculated profiles of ore and coke layers as they descend through the furnace. The calculation procedure was similar to that used in generating the results shown in Fig. 1(a), with the exception that it was based on: (a) solid inflow boundary condition determined from burden profiles predicted by a burden distribution model and (b) actual solid consumptions, including solid ore reduced to liquid iron, coke solution loss, coke combustion in the raceway and carburization of hot metal in the dripping zone and deadman.

Recently, Nogami et al. ${ }^{70)}$ implemented a Bingham-type model (used to describe the shear stress-shear rate relationship of a plastic fluid) into the viscous flow model to predict the stagnant zone and determine the solid viscosity. In this model, the effective viscosity of the solid phase is determined: $\mu_{\text {eff }}=\mu_{0}+\tau_{0} / \dot{\gamma}$, for $\tau>\tau_{0} ; \mu_{\mathrm{eff}}=\infty$, for $\tau \leq \tau_{0}$. Once the shear stress, $\tau$, is larger than the threshold stress (i.e. yield stress $\tau_{0}$ ), the solid starts to flow and effecitve viscosity is a function of shear rate. Conversely, the effective viscosity approaches infinity as the solid velocity tends to zero. The key coefficients, yield viscosity $\mu_{0}$ and yield stress $\tau_{0}$, are determined experimentally. In Fig. 2(a), the calculated time lines using the Bingham model are compared with the experimental data. ${ }^{70)}$ The macroscopic features of the flow show some discrepancies with the measured solid movement, indicating that Bingham model may be too simplistic to describe the complex stress field in the lower part of BF. The results do, however, highlight that the 


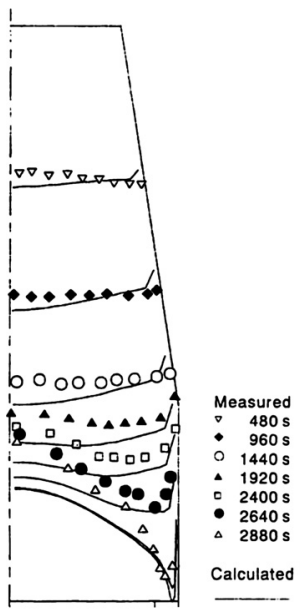

(a)

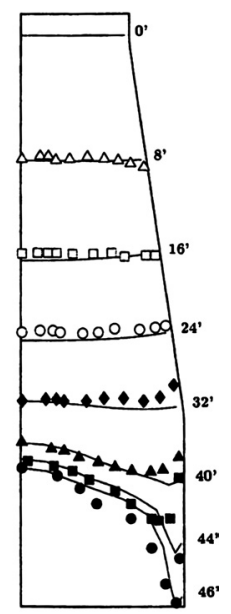

(b)
Fig. 2. Calculated (lines) and measured (points) time lines: (a) viscous model with Bingham fluid assumption for solids $^{70)}$; and (b) hypo-plasticity model for solids. ${ }^{71)}$

model is useful in determining the shape of the stagnant zone in a continuum model framework.

The solid phase may be treated as a plastic fluid so that elasto-plasticity $^{68)}$ and hypo-plasticity ${ }^{71,72)}$ theories can be employed to describe the stress-strain relation of solid particles. Inada et al. ${ }^{68)}$ analyzed the stress distribution in an actual blast furnace using elasto-plasticity theory to reproduce the measured vertical stress variation during burden charging. Zaïmi et al. ${ }^{71,72)}$ used the hypo-plasticity theory to describe solid flow behaviour, in which incremental equations for the stress and strain tensor increments are developed. In Fig. 2(b), application of the hypo-plasticity model shows a satisfactory prediction of the time lines and hence, stress field. However, future work needs to be done to test if the effects of other phases have been properly taken into account by these theories.

\subsubsection{Discrete Model}

The application of continuum-based models in predicting the microstructure of a particulate system is impossible. Hence, empirical equations have been used. The lack of quantitative fundamental understanding makes it difficult to generate a general method for reliable design and control/ optimization of processes. In recent years, discrete particle simulation, often developed on the basis of the DEM, has increasingly been used to simulate the solid flow in a BF.

The validity of the DEM approach has been assessed at different levels. ${ }^{57,73)}$ For example, in Fig. 3(a), the solid flow pattern observed from the physical experiment is shown. The four solid flow regions are clearly observed, with a stagnant zone generated in the lower central part. These solid flow zones can be reproduced in the present DEM simulation, ${ }^{57)}$ as shown in Fig. 3(b). In the continuum-based mathematical models, the profile of the stagnant zone is determined on the basis of plasticity theory, or applying the treatment by Tüzün et al., ${ }^{74)}$ so as to set the boundary conditions for solving the governing equations for the solid phase. These treatments are largely arbitrary in nature. However, in the discrete model, the stagnant zone is an outcome of the simulation.
DEM offers a convenient way to carry out controlled numerical experiments to study the solid flow in the BF shaft under various conditions. For example, a series of studies have been carried out to explore factors which influence the formation process of burden distribution and the effect of operational variables on the burden flow. ${ }^{65,75)}$ By this method, the solid descending behaviour in the furnace can be studied at a particle scale. Particle trajectories can be traced easily. Microscopic information, such as flow and force structures (i.e. velocity, porosity, coordination number, force), provides additional understanding of the solid flow within a BF, as shown in Fig. 4. With regards to the porosity distribution in a BF, DEM simulations reveal that the shaft can be divided into three main regions, as shown in Fig. 4(b): (1), lower porosity region (0.37-0.43), located in the hearth and deadman, where particles form a relatively dense packing to support the rest of the bed; (2), medium porosity region $(0.43-0.46)$, which mainly corresponds to plug flow; and (3), higher porosity region (0.460.48 , including the very high porosity raceway region), characterized by converging flow and high velocity particles. A snapshot of the normal particle force structure or distribution is shown in Fig. 4(c) where a connecting branch represents a particle-particle interaction and its thickness represents the magnitude of the normal force. It can be observed that the particles in the central bottom part experience large normal forces, and have strong force chains. This is because these particles need to support the particles above them. Conversely, particles exhibit weak force network around the raceway and in the fast flow zone. This is because particles in these regions are moving quickly and large voids exist among particles.

\subsection{Raceway}

Hot blast air is injected into the BF at high speed through the tuyeres, forming a cavity referred to as the raceway. Most of the coke and injected auxiliary fuels are burnt in the raceways to provide heat and reducing gases for the smelting and reduction process. The stability of the BF operation is closely related to the motion and packing state of coke particles in the vicinity of the raceway. Investigations have been carried out focusing on various aspects, including: i) general understanding of raceway phenomena ${ }^{76)}$; ii) formulation of empirical or semi-empirical correlations to describe the raceway properties such as the raceway depth and hysteresis phenomena ${ }^{77-80)}$; iii) numerical simulation of gas-solid flow in and around the raceway. In the numerical modelling of this gas-solid flow system, the solid phase can be considered as either continuous or discrete again, reflected in the two popular models for gas-solid flow in the metallurgical field, i.e. TFM and CCDM.

\subsubsection{TFM Approach}

As described in Sec. 2, TFM falls within the continuumbased modelling framework. Both gas and solid phases are treated as interpenetrating continua. In the model development, the dimension of the computational cell is much greater than the size of individual particles but still small compared with the size of process. Using this model, Aoki et al. ${ }^{35)}$ calculated the multi-directional particle flows within a raceway. However, for TFM, a force balance based 


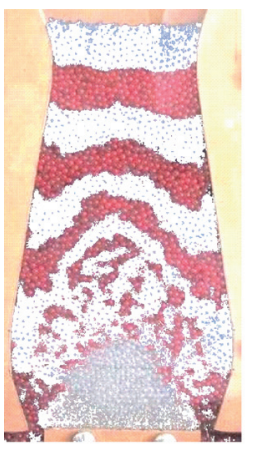

(a)

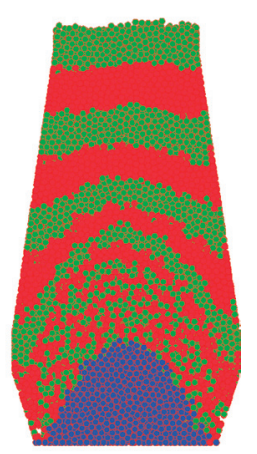

(b)

Fig. 3. Solid flow patterns observed in a small scale BF experimental rig (a) and calculated using the discrete particle simulation (b). ${ }^{57)}$

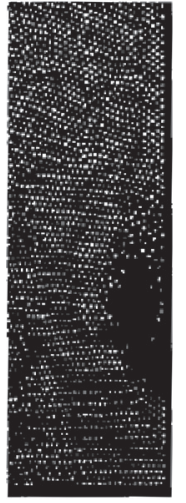

Measured

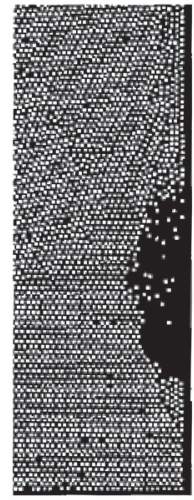

Calculated

(a)

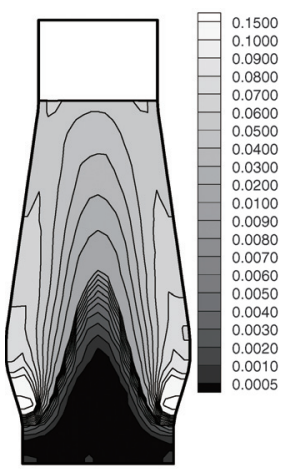

(a)

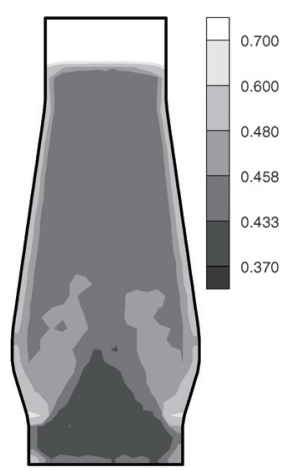

(b)

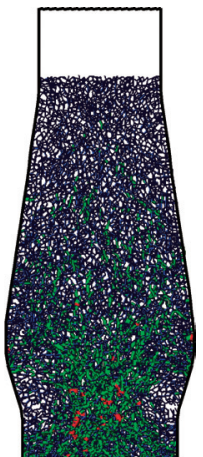

(c)

Fig. 4. (a) Time-averaged solid velocity field (units: $\mathrm{m} \cdot \mathrm{s}^{-1}$ ); (b) spatial porosity distribution; and (c) normal contact force structure. ${ }^{57)}$

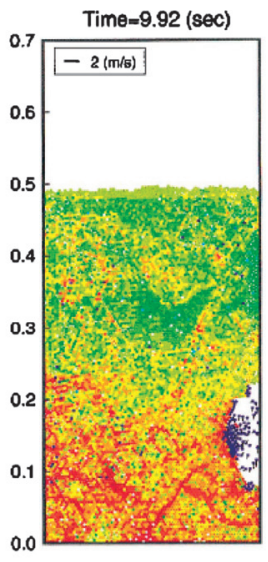

(b)

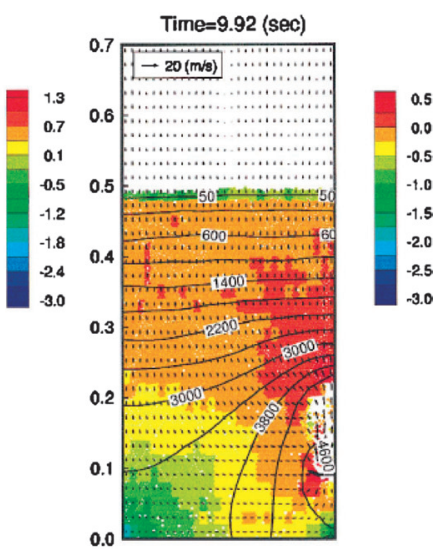

(c)

Fig. 5. (a) Measured $v s$. calculated solid flow patterns when gas velocity is $26 \mathrm{~m} \cdot \mathrm{s}^{-1},{ }^{60)}$ together with snapshots demonstrating the distribution of: (b) particle velocity (vector) and inter-particle force (contour); and (c) gas velocity (vector), isobars (line) and fluid drag force (contour). ${ }^{18)}$

on an empirical equation must be used to determine the raceway boundary. Instead, Mondal et al. ${ }^{36)}$ attempted to obtain the raceway geometry directly by using a two-fluid model coupled with the kinetic theory of granular flow. Unfortunately, detailed information, such as the solid velocity and porosity distribution, was not provided in their study. Although many efforts have been undertaken to predict the size and shape of the raceway under various conditions, the determination of the raceway boundary by the continuum approach is difficult. Furthermore, continuum-based modelling shows limited capability to describe the distribution of coke particles of different sizes within and around raceway and the movement of small coke.

\subsubsection{CCDM Approach}

The significant features of raceway phenomena are the strong gas-solid and solid-solid interactions. As solid particles are best considered discrete entities, CCDM is considered suitable for the study of the gas-solid flow. ${ }^{18-21,59,60)}$

Figure 5(a) shows a comparison between CCDM results and experimental measurements. ${ }^{60)}$ When gas is laterally blasted into 2-D packed bed, a cavity can form in front of the gas inlet, which is characterized by a central high void region with some particles circulating in the cavity. As demonstrated, the model predictions are in good agreement with the experiments both in terms of cavity size and internal particle circulating patterns. This particle-scale simulation also provides some new understanding of the gas-solid flow and forces in a raceway. As illustrated in Fig. 5(b), large inter-particle forces occur around the raceway boundary and propagate into the particle assembly in a complex manner. ${ }^{18)}$ Note that the so-called boundary is used to distinguish between evidently high void region and dense particle flow region for convenience of description. In CCDM, this boundary does not need to be especially defined, which differs from the continuum approach described above. The results suggest that particle breakage and hence, generation of fines, may take place within the raceway and around its boundary. Figure 5(c) shows the variation of the gas drag force around the raceway, in particular, the high drag forces near the top of the raceway, which supports the argument that the raceway roof is mainly supported by the fluid drag force. ${ }^{77)}$ Simulations have been extended to the study of more complicated flow phenomena, such as the hysteretic effect reflected in the relationship between pressure drop and gas velocity, ${ }^{18)}$ the effect of capillary and viscous forces 


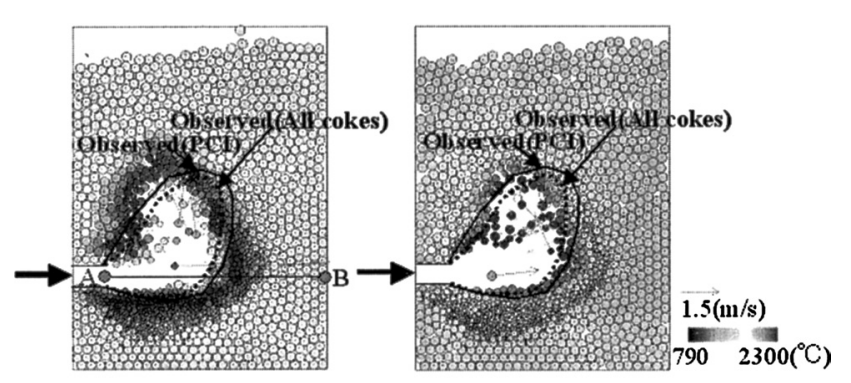

(a)

(b)

Fig. 6. Calculated and observed raceway shapes for two different operations $^{20)}$ : (a) all cokes; and (b) PCI.

induced by liquid phase, ${ }^{59)}$ and the effect of solid pressure (load) and coke consumption. ${ }^{19)}$ These results clearly show that the formation of raceway depends on a range of variables, which should be quantified very carefully.

Attempts have been made to extend the CCDM approach to consider heat and mass transfer, ${ }^{20)}$ and raceways with more realistic geometry. ${ }^{21)}$ Figure 6 shows CCDM calculations when chemical reactions and heat transfer in a raceway are considered. The shape and size of a raceway are calculated for both all coke operation and PCI operation, and compared with measurements from a high-temperature coke bed experiment. Both results show that the raceway shape with PCI is larger than that without PCI due to gas volume expansion inside the raceway. Interestingly, the model shows the formation of the raceway shell as a result of coke gasification and the resultant smaller coke particles percolating through and accumulating in the packed bed. The influence of blast conditions and top gas recycling on raceway formation has also been obtained, suggesting that: i) nitrogen enrichment may be effective in forming a uniform combustion zone in the low temperature atmosphere; and ii) for top gas recycling, a raceway may undergo various changes, e.g. increase in size and decrease in bosh gas volumetric flow rate.

\subsection{Hearth}

The coke bed in a BF, the core of which is often referred to as the deadman, extends to the hearth bottom or floats partially or completely in the liquid (hot metal and slag) bath. The state of the coke bed, i.e. its voidage, position and coke size, is known to influence the flow conditions, hot metal composition and temperature. Techniques have been developed for the determination of the bed voidage and slag levels in the hearth, using measurements of the hot metal removed from the hearth or pressure at the taphole. ${ }^{81,82)}$ These methods are invariably indirect. Numerical predictions of liquid levels or liquid flow distributions in the hearth are usually based on the static equilibrium of forces acting on the submerged solid particles or an assumed position of deadman and porosity distribution in the submerged solid region. ${ }^{83-92)}$ The prediction of the deadman profile and its relation to solid or liquid flow pattern overcomes these deficiencies. Due to the discontinuous stress distribution between solid particles in the hearth, a continuum-based approach is difficult to apply. Hence, in recent years, discrete approaches have been used to identify factors affecting the solid flow pattern and deadman profile in relation to particle-particle, particle-fluid and particle-wall interactions. ${ }^{22,50,93)}$
In the hearth, the liquid buoyancy force becomes significant because the density of fluid filling the voids among particles is high, even though the flow of fluid may be negligible. This can be demonstrated from the simple experiment shown in Fig. 7. The discrete approach can satisfactorily reproduce the phenomena (Fig. 7(b) vs. Fig. 7(c)). The results suggest that upward flow of particles, driven by the buoyancy force, occurs. Different solid flow patterns in BF hearth are possible. This is confirmed in the study of solid flow in a simplified BF hearth model (Fig. 8(a)). A large stagnant zone represented by grey particles is formed for a relatively shallow hearth (Fig. 8(b)). On the other hand, a deep hearth can generate a relatively large upward buoyancy force, which reduces the size of the stagnant zone (Fig. 8(c)). All of these results demonstrate that the solid flow patterns are strongly affected by the liquid level and the position of tapping hole due to the upward buoyancy force relative to gravity. ${ }^{22)}$ Such studies should be extended to more complicated conditions related to $\mathrm{BF}$ operations to develop a better understanding of the underlying physics and better control strategies.

As the molten liquids accumulate in and are removed from the hearth according to the casting schedule, coke in the deadman may be continuously renewed. A quantitative analysis of deadman renewal behaviour has been made based on particle trajectories and particle discharging rates. ${ }^{93,94)}$ Coke gradually moves towards the raceway as the bed floats and sinks, corresponding to the change of liquid level. This motion is characterised by older coke particles moving out from the deadman during bed floating and newer particles coming into the deadman during bed sitting periods. The older particles along the surface layer of deadman are found to be renewed relatively easily and quickly with the up and down motion. Particles near the furnace centre are also gradually renewed. The numerical analysis shows that the new particles come into the deadman mainly through a small area near the top of deadman. This is in agreement with observation by Takahashi et al., ${ }^{95)}$ as shown in Fig. 9.

\section{Gas-powder Flow}

One of the most significant changes in the modern blast furnace technology is the introduction of PCI operation and subsequent increase in PCI levels. As the PCI rate increases, unburnt coal or char enters the furnace together with reducing gas. Unburnt coal or char, and coke (and possibly ore) fines constitute the powder phase in a $\mathrm{BF}^{96}$ ) These fines, if not consumed, exist in the furnace as static or dynamic holdup. Previous studies on the flow characteristics of powder in 1D and 2D geometries aimed to i) identify the relationship between pressure loss, powder holdup

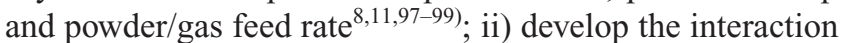
force between powder and solid particles which is widely accepted in the subsequent continuous modelling ${ }^{38,40,41)}$; iii) examine some special phenomena such as blockade ${ }^{8)}$ and hanging. ${ }^{23)}$ Deficiencies in these studies are inherited in mathematical modelling, including, for example, the ignorance of the static holdup, the use of a relatively simple packing structure, and different interaction force equations. In order to overcome these deficiencies, various experimen- 


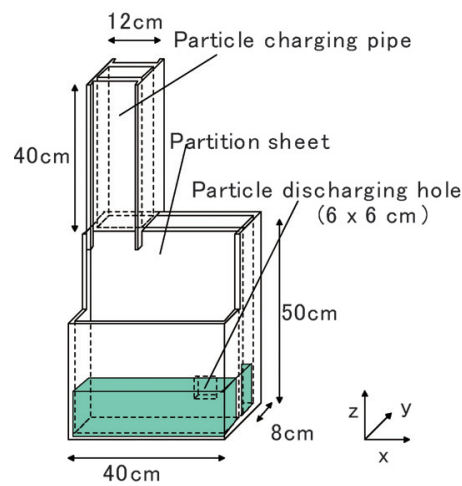

(a)

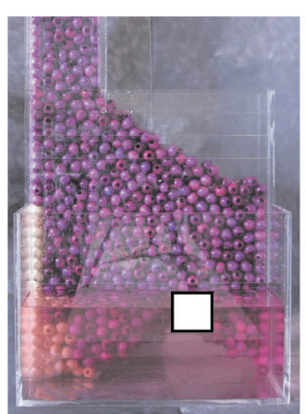

(b)

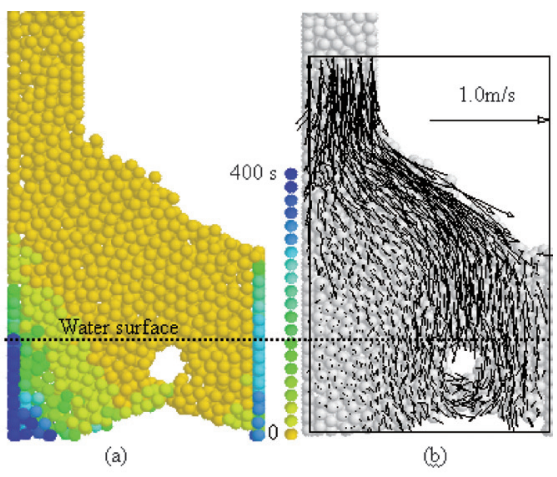

(c)

(d)

Fig. 7. (a) Schematic illustration of the physical model used; (b) observed solid flow patterns; (c) calculated flow patterns (the color displays the residence time distribution); and (d) solid velocity field. ${ }^{22)}$

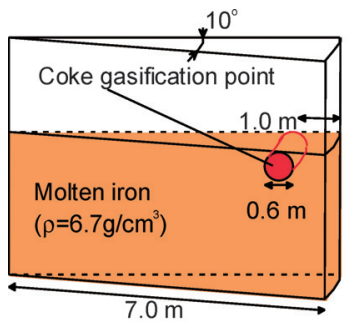

Simulated hearth section

(a)

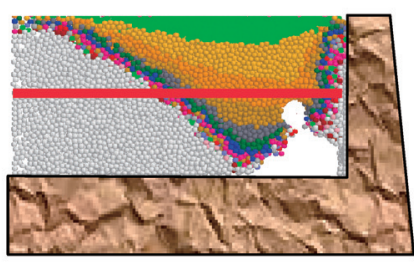

(b)

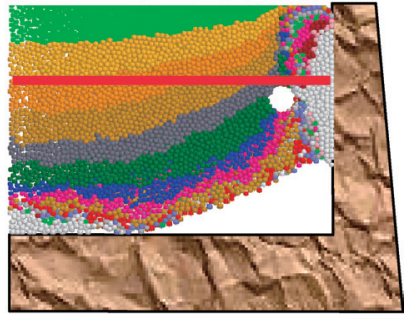

(c)

Fig. 8. Geometry of a sectioned hearth model (a) spatial distribution of particles of different residence time in a shallow hearth (b) and deep hearth (c) where the red line represents the liquid level, grey particles are those originally in the hearth and the colour of particles changes every $0.5 \mathrm{~s}^{22}$ )

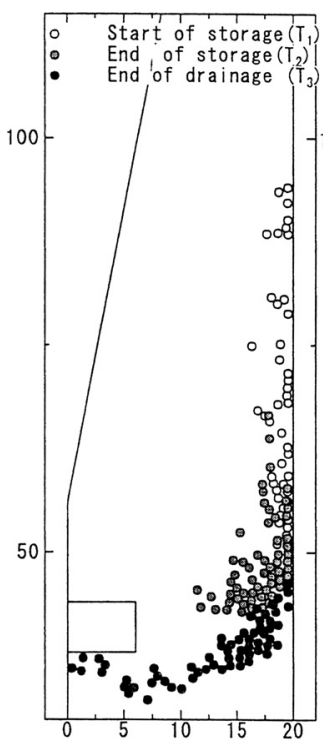

(a)

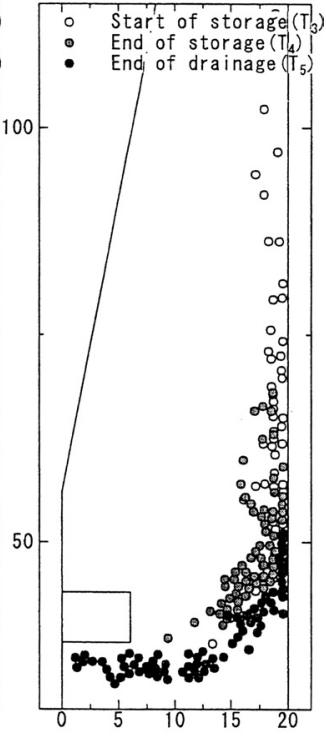

(b)
Fig. 9. Locations of particles that have renewed deadman at different times. ${ }^{93)}$ (a) first storing and tapping; and (b) second.

tal $^{24,40,100-104)}$ and numerical ${ }^{21,38,40-42,96,105-109)}$ efforts have been made by various investigators in recent years.

\subsection{Numerical Modelling}

Once again, from the viewpoint of the scale on which a

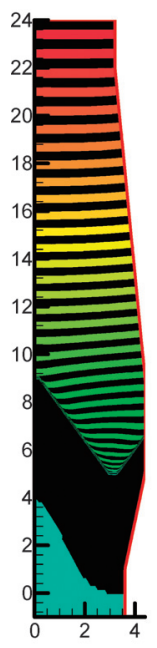

(a)

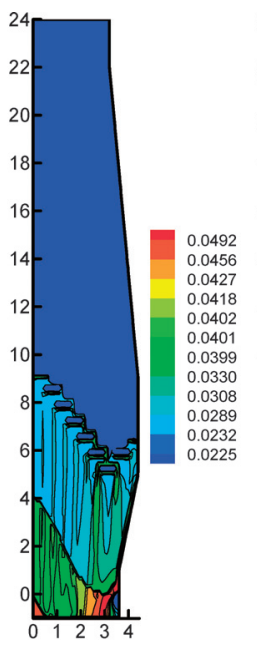

(b)

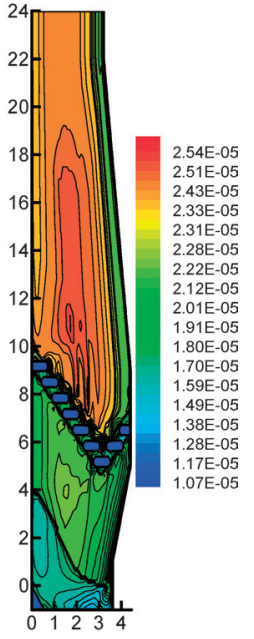

(c)
Fig. 16. Multiphase flow pattern in terms of (a) solid timelines; (b) dynamic liquid holdup; and (c) dynamic powder holdup. ${ }^{128)}$

model captures powder flow in a packed bed, the existing approaches can be classified into two categories: discrete and continuum. In the discrete approach, two treatments have been adopted to overcome difficulties in dealing with a large number of particles and lack of computational power. In the first treatment, inter-particle interaction and influence of powder phase on conveying fluid are ignored so that the 
Table 3. Summary of the continuum models applied to gas-powde-solid flow.

\begin{tabular}{|c|c|c|c|c|c|c|c|c|}
\hline Refs. & $\begin{array}{l}\text { Time } \\
\text { term }\end{array}$ & $\begin{array}{l}\text { Convective } \\
\text { Term }\end{array}$ & $\begin{array}{l}\text { Viscous } \\
\text { term }\end{array}$ & $\begin{array}{l}\text { Pres- } \\
\text { sure }\end{array}$ & $\mathbf{F}_{\mathrm{gf}}$ & $F_{\mathrm{fs}}$ & Gravity & $\begin{array}{l}\text { Dimen- } \\
\text { sion }\end{array}$ \\
\hline Fan et al. ${ }^{111)}$ & $\sqrt{ }$ & & & & $\sqrt{ }$ & $\sqrt{ }$ & $\sqrt{ }$ & $1-\mathrm{D}$ \\
\hline Yamaoka $^{23)}$ & $\sqrt{ }$ & & & & $\sqrt{ }$ & $\sqrt{ }$ & & $2-\mathrm{D}$ \\
\hline Shibata et al. ${ }^{12)}$ & & $\sqrt{ }$ & & & $\sqrt{ }$ & $\sqrt{ }$ & & $2-\mathrm{D}$ \\
\hline $\begin{array}{l}\text { Austin et al. }{ }^{38)} \\
\text { Nogami et al }{ }^{96)}\end{array}$ & & $\sqrt{ }$ & & & $\sqrt{ }$ & $\sqrt{ }$ & $\sqrt{ }$ & $2-\mathrm{D}$ \\
\hline Yamagata et al. ${ }^{12)}$ & $\sqrt{ }$ & & & & $\sqrt{ }$ & $\sqrt{ }$ & $\sqrt{ }$ & $2-\mathrm{D}$ \\
\hline Van der Ham et al. ${ }^{10)}$ & $\sqrt{ }$ & & & & $\sqrt{ }$ & $\sqrt{ }$ & $\sqrt{ }$ & $1-\mathrm{D}$ \\
\hline Yagi $^{1)}$ & $\sqrt{ }$ & $\sqrt{ }$ & & $\sqrt{ }$ & $\sqrt{ }$ & $\sqrt{ }$ & $\sqrt{ }$ & $2-\mathrm{D}$ \\
\hline Chen et al. ${ }^{40)}$ & & $\sqrt{ }$ & & & $\sqrt{ }$ & $\sqrt{ }$ & & $2-\mathrm{D}$ \\
\hline Sugiyama et al. ${ }^{107)}$ & $\sqrt{ }$ & & & & $\sqrt{ }$ & $\sqrt{ }$ & $\sqrt{ }$ & $1-\mathrm{D}$ \\
\hline Dong et al. ${ }^{41)}$ & & $\sqrt{ }$ & $\sqrt{ }$ & $\sqrt{ }$ & $\sqrt{ }$ & $\sqrt{ }$ & $\sqrt{ }$ & $2-\mathrm{D}$ \\
\hline Li et al. ${ }^{42)}$ & & $\sqrt{ }$ & $\sqrt{ }$ & $\sqrt{ }$ & $\sqrt{ }$ & $\sqrt{ }$ & $\sqrt{ }$ & $2-\mathrm{D}$ \\
\hline
\end{tabular}

NB: empty box means the term is not considered.

phase can be simulated in a Lagrangian frame of reference. The approach can track the trajectory of a single particle or a powder cluster through a computational domain by solving the Lagrangian equations below ${ }^{105,110)}$ :

$$
\frac{d \mathbf{u}_{f}}{d t}=\frac{1}{2 \rho_{f}} C_{d f} a_{g f} \rho_{g}\left(\mathbf{u}_{g}-\mathbf{u}_{f}\right)+\mathbf{g}+f_{k} \mathbf{u}_{f} \ldots \ldots
$$

The second treatment is based on the combination of a hard sphere model and direct simulation using the Monte Carlo method, ${ }^{21,106)}$ in which the field of real particles is represented by a field of sampled particles so that the computational time is reduced significantly. This differs from the above discrete element approach in that collisions between sampled particles are determined by the collision probability which needs to be determined a priori. The key collision probability between the $i$ th and the $j$ th sampled particles during $\Delta t$ is defined as follows:

$$
P_{i j}=\frac{n}{N} \pi \bar{D}_{p}^{2}\left|\mathbf{u}_{p i}-\mathbf{u}_{p j}\right| \Delta t / V_{0}
$$

There are however limitations associated with these two treatments. For example, the former is only applicable to dilute flow, allowing the collision and contact of powder particles to be ignored and a limited number of powders tracked; the latter is applicable to medium dense flow. For high powder concentrations, the sampled particle technique cannot represent the realistic flow condition due to flow being dominated by the contact forces between particles.

In the continuum approach, gas and powder phases are both assumed continuous. Traditionally, TFM is used for this type of fluid flow, where separate momentum and continuity equations are used for each phase. The governing equations are described in Sec. 2 (Eqs. (1) and (2)), and formulated based on the volume-averaging or time-averaging theorem. In actual implementation, different simplifications and/or assumptions have been made to calculate gas-powder flow in a packed bed. As listed in Table 3, corresponding to these simplifications/assumptions, some terms in the original governing equations are ignored.
These numerical models differ in their descriptions of the governing equation, the interaction correlation between powder and solid and the computational approach for powder holdup. All of these models are only used to simulate dynamic powder holdup, i.e. powder transported by gas. The static powder holdup or powder transported by packed particles, is obtained using empirical correlations ${ }^{41,113)}$ or calculated by material balances using empirical expressions on powder deposition rate and equilibrium static holdup. ${ }^{108,109)}$

In some cases, powder may deposit in regions of low gas velocity, where the void space among packed particles can be completely filled with powder. This region is referred to as the powder accumulation region, which has the maximum powder holdup and will not allow any powder to penetrate. ${ }^{24)}$ In order to determine this accumulation region and gas-powder flow simultaneously, a solution technique has been proposed to treat the region as part of the boundary for powder phase. ${ }^{41)}$

\subsection{Model Findings}

Most of unburnt char or coke fines generated around the raceway can be consumed by in-furnace reactions such as solution loss, direct reduction or carburization. Before consumption, some powders may deposit in a region of low gas velocity, which may deteriorate the stable BF operation. For example, Yamaoka ${ }^{23}$ ) observed that hanging phenomena can occur, with a large amount of dust deposits on particle surfaces in front of a gas-powder inlet. In theory, when gas velocity is lower than a critical transport velocity, powder can continuously deposit until the voids of the packing are fully closed off by powder. In this case, the so-called powder accumulation region can be observed in a laboratorial scale apparatus. ${ }^{24)}$ This is shown in Fig. 10, where a CZ is represented by a series of blocks. Once the accumulation region attains a critical shape and configuration, gas flow in the vicinity of the accumulation region becomes strong and the momentum exchange between gas and powder increases so that no more powder can deposit. The undeposited powder can be entrained by gas phase. As the flow approaches a 


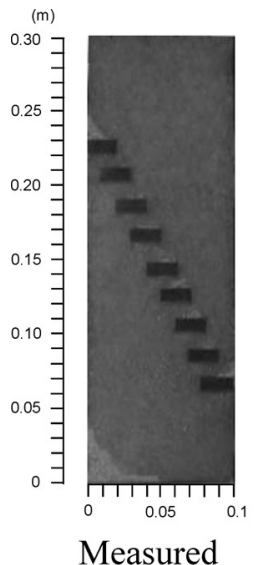

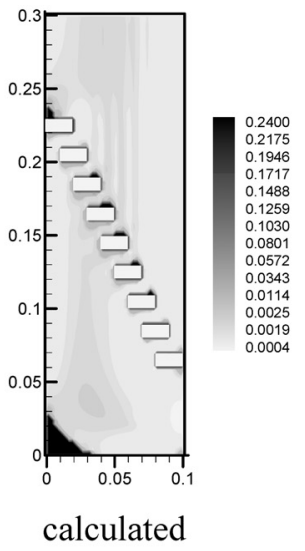

(a)

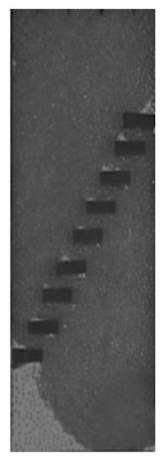

Measured

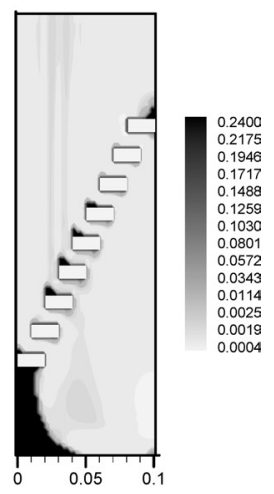

calculated

(b)

Fig. 10. Comparison between the experimental and calculated powder accumulation regions in inverse V-shaped CZ (a) and V-shaped CZ (b) when $U_{g}=0.5 \mathrm{~m} \cdot \mathrm{s}^{-1}, G_{f}=0.51 \mathrm{~kg} \cdot \mathrm{m}^{-2} \cdot \mathrm{s}^{-1}$ : left, experimental, ${ }^{24)}$ right, calculated. ${ }^{41)}$

block, powder flow is considerably hindered. As a result, powder holdup increases beneath the block where upward gas velocity is relatively low. Some powder accumulates on the block because of the convergence of gas streamlines.

Dong et al. ${ }^{41)}$ have modelled this flow behaviour. Figure 10 shows the calculated total hold-ups as contours of powder volume fraction. The good agreement between the measured and simulated results confirms, at a macroscopic level, the validity of the proposed model and solution procedure. A comparison of different $\mathrm{CZ}$ shapes and their effect on powder accumulation shows that the root height of the $\mathrm{CZ}$ has little effect on powder accumulation. However, the inclined angle of the $\mathrm{CZ}$ has a significant effect because of the changes in permeability and area for gas flow. ${ }^{24}$

An attempt has been made to extend the approach to BF operation. The calculated total powder holdup distribution is shown in Fig. 11. ${ }^{114)}$ A powder accumulation region can also be identified in the lower part of the BF. For different CZ shapes, the powder distribution shows significant differences. For the W-shaped CZ, a relatively dense powder distribution occurs in the lowest part of the CZ. For the inverse- $\mathrm{V}$ shaped $\mathrm{CZ}$, there is a denser powder distribution near the wall. For the $\mathrm{V}$-shaped $\mathrm{CZ}$, low gas velocity in the furnace center causes denser powder holdup in comparison to the other two shapes. In general, powder is likely to accumulate in the low gas flow region as previously described. From the inlet to accumulation region, total powder holdup gradually becomes higher. In the $\mathrm{CZ}$, the increased gas velocity induces low powder holdup in the coke slits between the impermeable fused ore layers. However, at the corner of some layers, powder can still accumulate due to the convergence of gas streamlines, such as at the upper part of $\mathrm{V}$ and inverse $\mathrm{V}$-shaped CZs.

It is worth to note that the above simulation is carried out without considering powder consumption. In the real BF operation, powder may be consumed in different ways such as gasification, carburization or being carried away by moving solid particles or liquid phase. All these consumptions may affect powder holdup distribution. If the consumption rate is higher than the accumulation rate, the region of powder accumulation in the hearth as shown in Fig. 11 will disappear. More work in this direction should be done in the
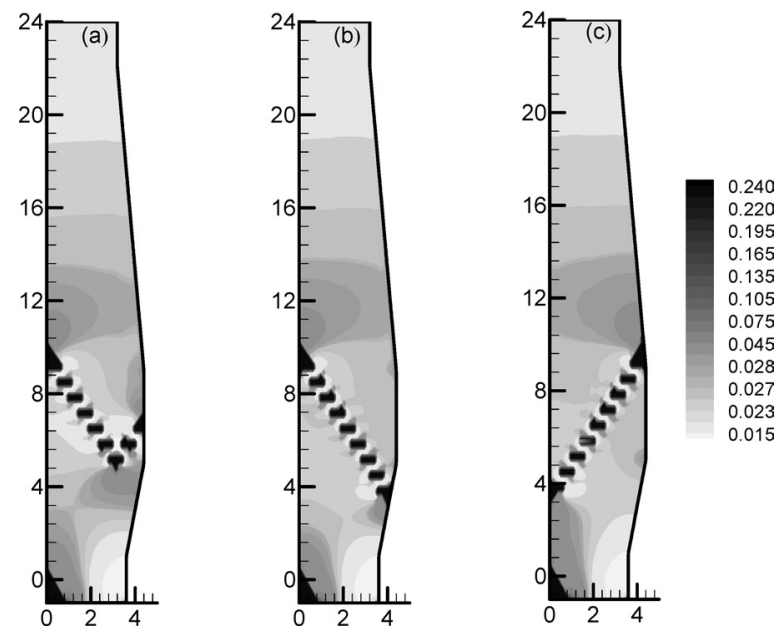

Fig. 11. Computed powder total holdup for different $\mathrm{CZ}$ shapes ${ }^{114)}$ : (a) W; (b) inverse V; and (c) V.

future to fully understand the flow and accumulation of powder phase in a BF.

\section{Gas-Liquid Flow}

Dissection studies of quenched blast furnaces demonstrate the existence of a cohesive zone where the liquid iron and slag are generated from reduced and melted ferrous materials. ${ }^{2)}$ The generated liquid trickles down through the coke bed to the hearth. During this process, intensive interaction, heat and mass transfer take place between liquid and other phases. In the past, many efforts have been made to understand the gas-liquid flow in a BF, particularly the liquid flow regimes and spatial distribution of holdup. ${ }^{2)}$ The previous work is usually on a macroscopic scale. However, recent experimental studies demonstrate there is a need for understanding on a microscopic scale, which is more related to the characteristics of localized gas-liquid flow, such as i) an unsaturated liquid percolates through a packed bed as a series of rivulets or drops ${ }^{15)}$; ii) localized upward liquid, saturation and flooding may occur in the cohesive zone, where strong gas flow and gas-liquid interaction exist ${ }^{25}$; iii) the effect of packing property on liquid flow is signifi- 
cant, resulting in enhanced liquid channeling flow with an initial unsoaked bed and large voidage close to wall, increased liquid dispersion with increasing surface tension $^{116-119)}$; iv) slag may exist in a BF as a non-wetting or wetting liquid depending on its reaction with coke, and slag and iron flows may be closely coupled, i.e. interacting flows. ${ }^{120)}$ A number of attempts have been made to develop mathematical models to describe these complicated gasliquid flow phenomena in packed beds relevant to the BF.

\subsection{Numerical Models}

A few early models have been proposed to simulate the liquid flow below the blast furnace cohesive zone, including the potential flow, ${ }^{4,15)}$ the probability model, ${ }^{13)}$ probabilitycontinuous model, ${ }^{14)}$ and tube network dynamic model. ${ }^{121)}$ The first three models have been summarized by Yagi. ${ }^{1)}$ These models can describe the liquid flow pattern and holdup distribution in a BF to some degree. Actually, the continuous model has been implemented in BF four-fluid flow modelling. ${ }^{38)}$ However, there are various problems with these early models. For example, the potential and the probability-continuous models do not properly take into account the discrete flow features of liquids as experimentally elucidated by Gupta el al. ${ }^{115)}$ On the other hand, the tube network dynamic model is computationally very demanding, at least conceptually so. Moreover, it should be pointed out that these studies are mainly oriented to gas and liquid flow below, rather than within, the cohesive zone. Recent physical experiments indicate that due to the sharp change of permeability and gas flow pattern in the cohesive zone, a strong localised liquid flow involving downward, horizontal or even upward flow is possible.

One promising way to describe gas-liquid flow in a BF is the so-called force balance approach, which describes liquid flow as rivulets or droplets under the influence of gravity, gas drag and bed resistance. Gupta et al. ${ }^{115)}$ proposed some of the concepts involved in the original force balance model, but they did not formulate a mathematical model that can be analytically or numerically applied to liquid flow simulation. Strictly speaking, force balance does not apply to a single drop which may accelerate or decelerate during its motion in the voids of packed particles, but to a macro computational cell equivalent to the continuum approach described above. Moreover, liquid droplet or rivulet flow through a packed bed is dominated not only by the gravity and drag forces but also by the complex pore geometry formed by the packing particles. This effect is characterized by the liquid dispersion in a certain flow region, giving a stochastic contribution to the main flow stream. With these realizations, Wang et al. ${ }^{16,17)}$ developed a liquid flow model which is composed of a liquid flow sub-model featured by the force balance that applies to discrete liquid flow and a liquid dispersion sub-model to consider the stochastic motion that relates to the packing geometry. The main features of the two sub-models are descibed as follows.

- Liquid flow sub-model: The equation of motion for the liquid phase can be described as follows:

$$
\mathbf{F}_{l}^{g}+\mathbf{F}_{l}^{s}+\mathbf{F}_{l}^{\text {gravity }}=0 .
$$

where the gas drag force $\mathbf{F}_{l}^{g}$ and the bed resistance force $\mathbf{F}_{l}^{s}$ can be respectively written as

$$
\mathbf{F}_{l}^{g}=1 / 2 C_{d g} a_{g l} \rho_{g}\left|\mathbf{U}_{g}-\mathbf{U}_{l}\right|\left(\mathbf{U}_{g}-\mathbf{U}_{l}\right) .
$$

and

$$
\mathbf{F}_{l}^{s}=1 / 2 C_{d s} a_{s l} \rho_{l}\left|\mathbf{U}_{l}\right| \mathbf{U}_{l}
$$

Equations (8) and (9) are dependent on a large number of variables which are related to microstructural properties such as the size and shape of liquid droplets, and the size and shape of pores. Some empirical equations have been formulated to quantify the dependency. ${ }^{122-124)}$

- Liquid dispersion sub-model: The stochastic flow phenomenon is described under the following conditions:

i) A stochastic velocity is assumed to be normal to the main flow direction of liquid determined by the force balance equation; and

ii) The stochastic velocity has a distribution given by:

$$
f\left(U_{s}\right)= \begin{cases}\frac{U_{s 0}+U_{s}}{U_{s 0}^{2}} & \left(-U_{s 0} \leq U_{s} \leq 0\right) \\ \frac{U_{s 0}-U_{s}}{U_{s 0}^{2}} & \left(0<U_{s} \leq U_{s 0}\right) \\ 0 & \left(\left|U_{s}\right|>U_{s 0}\right)\end{cases}
$$

$U_{s 0}$, the maximum stochastic velocity, should be a function of liquid, gas and solid properties. In connection with Eqs. (8) and (9), some work has been done in order to generalize an equations for its evaluation. ${ }^{17)}$ Based on this distribution, the relevant probability for liquid dispersion from a given point towards neighbouring nodes could be obtained. For each computational node, the amount of liquid flowing in must be equal to the sum of liquid flowing out to maintain mass conservation. Suitable boundary conditions for liquid dispersion have also been proposed. ${ }^{17,125)}$

Simulation of the liquid flow can be achieved by coupling these two sub-models. A corresponding solution technique has been developed by Wang et al. ${ }^{16,17,125)}$

\subsection{Model Validation and Application}

The above model has been validated by comparing predicted and measured liquid flow distributions for different gas and/or liquid flow conditions, and bed structures. Figure 12 shows typical measured and calculated liquid flow profiles for different gas flow rates. ${ }^{16)}$ The two liquid flow conditions in Fig. 12 may be associated with different BF operating conditions. For example, the downward flow in Fig. 12(a) may be related to liquid flow in the dropping zone, while the cross- and co-current flows in Fig. 12(b) may be related to liquid flow through coke slits in the cohesive zone. Theoretically, liquid may disperse in an infinitely large region so that the so-called theoretical region can give the maximum possible flow region. However, in the implementation of the numerical scheme, only the region with relatively high frequency probabilities needs to be considered. Figure 12(c) shows this probability distribution as a function of height for the case shown in Fig. 12(a). Thus, focused on the region carrying, say, $99.5 \%$, of the liquid flow, one can identify the actual liquid flow region. As shown in Fig. 12(a) and (b), the predicted liquid flow pro- 


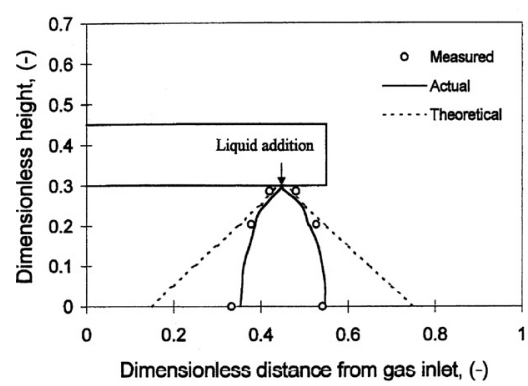

(a)

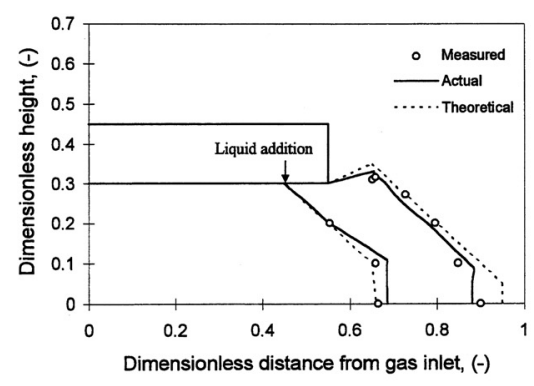

(b)

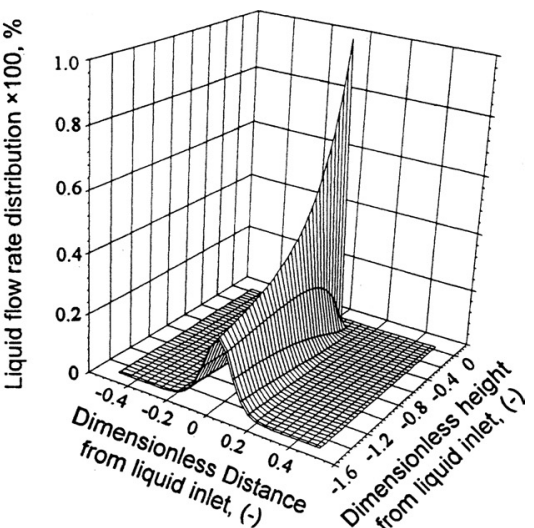

(c)

Fig. 12. Liquid flow profiles in the simulated BF cohesive layer at different gas flow rates (horizontal inlet at the left bottom corner) ${ }^{16)}$ : (a) $0 \mathrm{~m}^{3} \cdot \mathrm{s}^{-1}$; (b) $0.012 \mathrm{~m}^{3} \cdot \mathrm{s}^{-1}$; and (c) liquid flow rate distribution as a function of height for a central inlet flow bed corresponding to Case (a).

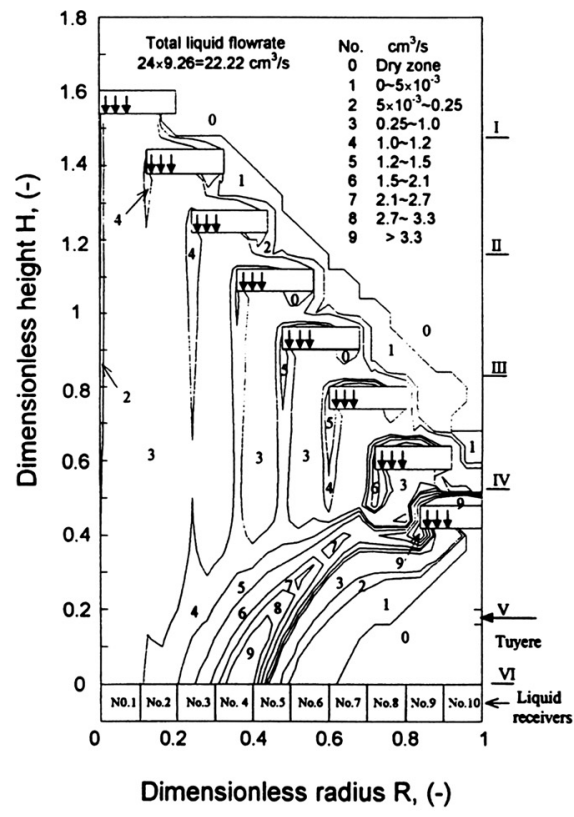

(a)

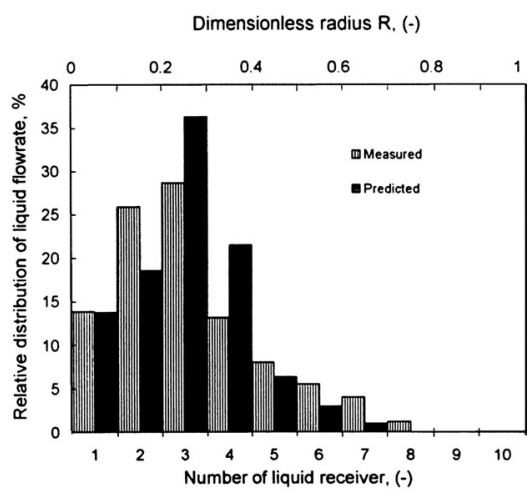

(b)

Fig. 13. (a) Predicted liquid flow rate distribution in a simulated blast furnace lower zone; and (b) comparison between predicted and measured liquid flow rate distributions at the bottom outlet. ${ }^{17)}$

files can match the measured liquid flow profiles satisfactorily. Both experimental and numerical results suggest that if gas flow rate is high, liquid will flow up and around the "fused layer".

The approach has been tested for a two-dimensional slot model, comprising a multi-layer inverse- $\mathrm{V}$ cohesive zone situated above a side-entry tuyere. Physically, liquid (water) was introduced through each of the impermeable 'fused' layers and collected at ten equally spaced sections in the base. Compressed air was introduced through the tuyere and exited at the top of the bed. Liquid was strongly deflected away from the tuyere and, in the cohesive zone, some liquid was forced towards the 'lumpy' zone, flowing along the top side of the cohesive zone profile. Figure 13(a) gives the calculated liquid flow rate distribution and Fig. 13(b) compares the predicted liquid flow rate with measurements at the bottom collectors. ${ }^{17)}$ Obviously, the model can describe the liquid flow satisfactorily.

The strong interaction between gas and liquid flows discussed above highlights the importance of understanding the gas and liquid flows within the layered $\mathrm{CZ}$ in a $\mathrm{BF} .{ }^{125}$ ) Different shaped cohesive zones give different gas and hence liquid flow patterns. The force balance model would provide a convenient way to enhance the current understanding of the liquid flow and its relation to the cohesive zone. Figure 14 shows the simulated liquid flow patterns for three typical cohesive zones: inverse $\mathrm{V}, \mathrm{V}$, and $\mathrm{W}$ shaped. In line with the experimental efforts, ${ }^{2,25)}$ the following features can be identified: 1) liquid may migrate from top to low fused layers in the cohesive zone, giving a nonuniform distribution of liquid flow rates; 2) liquid drips down in the form of "icicles" in the region near the $\mathrm{CZ}$ and liquid flow may accumulate and/or form a strong stream at the root of the cohesive zone; 3 ) the liquid flow near the 


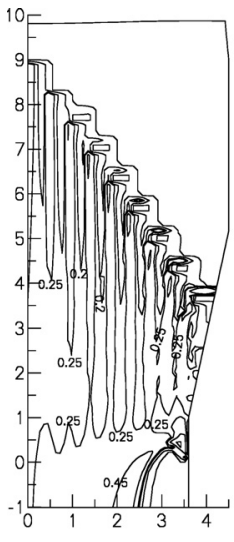

(a)

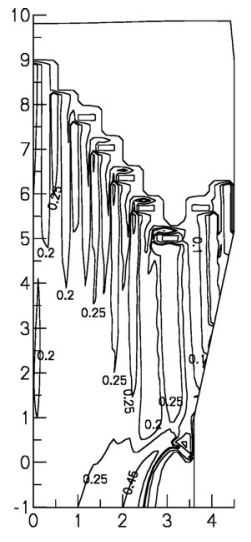

(b)

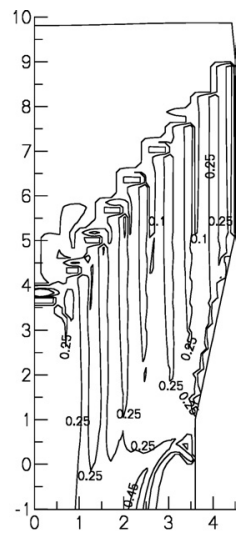

(c)
Fig. 14. Liquid flow patterns under the different $\mathrm{CZ}$ shapes ${ }^{125)}$ : (a) inverse V; (b) W; and (c) V.

raceway is strongly shifted by gas flow and then re-distributed in the lower zone. It is worth to mention that the effect of gas phase on liquid flow may be reduced in an actual three-dimensional BF, especially near the raceway, as there is a region between tuyeres where liquid could drop with less gas interference.

The force balance model has been integrated into a comprehensive model of the BF process and applied to study the liquid flow and thermal-chemical behaviour in one of BlueScope Steel blast furnaces. ${ }^{126)}$ It shows that liquid flow behaviour is strongly linked to the bed permeability and furnace productivity. The decrease in porosity of the deadman induces a localized increase in the total liquid holdup. Similar to the previous results, ${ }^{38)}$ liquid metal generated in the cohesive zone is not noticeably affected by gas flow except in the vicinity of the raceway, with some deflection of the vectors away from the gas source.

\section{Multiphase Flow}

It is important to extend the modelling work from twophase flow to multiphase flow. It seems that not so much progress has been made in this direction, and the research efforts are more related to the application of existing knowledge since the review of Yagi. ${ }^{1)}$ This is because quantitative analysis of the interactions between phases and detailed prediction of multiphase flow in a BF are very difficult. Nonetheless, a few attempts have been made to tackle this problem in the following aspects: i) prediction of flooding phenomena ${ }^{127)}$; ii) quantification of the interactions between phases, particularly between powder and liquid ${ }^{43)}$; and iii) simulation of the multiphase flow. ${ }^{128)}$

\subsection{Flooding Diagram and Liquid-Powder Interaction}

Flooding may result in an increased pressure drop and unstable operation in a BF. Many studies have been conducted in the past to estimate the flooding point. They have led to the SLE (Sherwood-Leva-Eckert) flooding diagram and its subsequent modification. ${ }^{129,130)}$ For BF operation, such a diagram has been well established. ${ }^{131)}$ However, previous studies mainly focused on gas-liquid flow in fixed beds. There are a number of factors not properly considered, including, for example, the effects of solid flow and

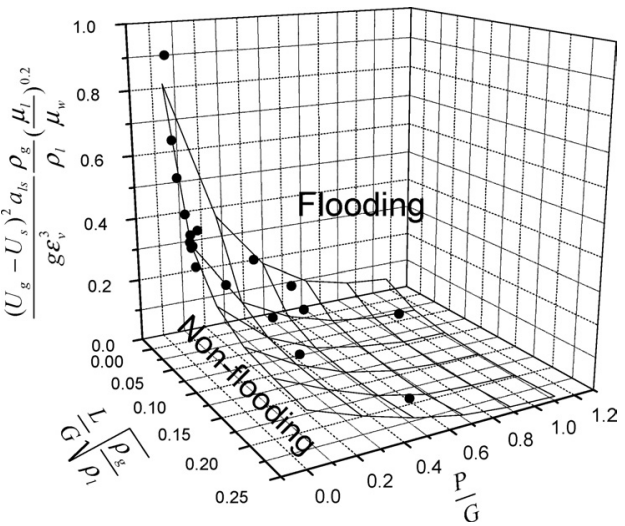

Fig. 15. Flooding diagram for gas-powder-liquid flow in moving bed when solid velocity $=0.3 \mathrm{~mm} \cdot \mathrm{s}^{-1}$ (points: experimental). ${ }^{127)}$

the presence of powder phase.

Pham et $a l .{ }^{132}$ have experimentally studied the four-fluid flow under conditions similar to BF lower zone, involving the upward gas and glass powder flow and the downward glass beads and water flow. They identified two regions for this gas-powder-liquid-particle flow system: operational and non-operational, with the former giving steady flow while the latter unsteady (unstable) flow. The non-operational flow gives a sharply increased pressure drop, i.e. the so called "flooding". Based on their results, a flooding diagram $^{127)}$ for the four fluid system has been established in terms of

$$
\begin{aligned}
& \text { flooding factor } \frac{\left(U_{g}-U_{s}\right)^{2} a_{l s}}{g \varepsilon_{v}^{3}} \frac{\rho_{g}}{\rho_{l}}\left(\frac{\mu_{l}}{\mu_{w}}\right)^{0.2} \\
& \text { fluid ratios } \mathrm{Fl}_{1}=\frac{L}{G} \sqrt{\frac{\rho_{g}}{\rho_{l}}}, \text { and } \mathrm{Fl}_{2}=\frac{P}{G}
\end{aligned}
$$

as shown in Fig. 15 when solid velocity is $0.3 \mathrm{~mm} \cdot \mathrm{s}^{-1}$. Above and below the fitting surface are respectively the flooding and non-flooding regions. Non-flooding region shrinks quickly with increasing powder and liquid flow rate. Therefore, flooding may occur locally in a BF, in regions with high powder or liquid flow rates.

In an Eulerian framework, four phases are treated mathematically as interpenetrating continua. Successful application of averaged partial differential equations to describe the motion of fluids and track the volume fraction distribution of each phase is dependent on the appropriate closure law for the interactions between the phases. Various correlations have been proposed for these interactions in gas-liquid-solid flow or in gas-powder-solid flow system. ${ }^{1)}$ However, to date, limited efforts have been made for the gas-powder-liquid-particle four-fluid flow, although the need for quantification of powder-liquid interaction has been recognized for years. Establishment of a steady state four-fluid flow is important to such quantification but this is somehow difficult to achieve for fixed beds. ${ }^{133)}$ This difficulty can be overcome in moving bed operations, as described above. On this basis, it is possible to quantify some interaction forces between phases for the four-fluid flow, as done recently by Chen. ${ }^{43)}$ For the air-water-glass powderglass beads flow system, the investigator formulated the fol- 
lowing empirical equation to describe the liquid-powder interaction forces by regression analysis of the experimental data generated based on different phase flow rates:

$$
\begin{aligned}
& \mathbf{F}_{l}^{f}=-6.15 \times 10^{-9} \operatorname{Re}_{l}^{0.798} \mathrm{Fr}_{s}^{-1.966} \mathrm{Fr}_{f}^{1.096} \operatorname{Re}_{g}^{4.31} \\
& \times\left(\mathbf{u}_{l}-\mathbf{u}_{f}\right) /\left|\mathbf{u}_{l}-\mathbf{u}_{f}\right| \ldots
\end{aligned}
$$

when $R e_{g} \in(81,110), R e_{l} \in(0,1.16), F_{f} \in(0.0003,0.002)$, and $F r_{s} \in(0,0.0052)$. Within the experimental ranges considered, the interaction force between powder and liquid increases as gas, powder and liquid flow rates increase and decreases with increasing solid flow rate.

\subsection{Simulation of the Multiphase Flow}

Attempts have also been made to extend the modelling work from two-phase flow to multiphase flow in a $\mathrm{BF},{ }^{128)}$ using the recently developed concepts and techniques $^{16,34,41,122,126)}$ to calculate solid stagnant profile, powder accumulation and liquid flow pattern. As an example, Fig. 16 (on Page 1560) shows some typical solid, liquid and powder flow patterns. The results indicate that i) complex flow regions co-exist in a $\mathrm{BF}$, including solid stagnant region, powder accumulation region and liquid dry zone; ii) the flow is highly non-uniform, particularly for liquid and powder phases; and iii) there is strong coupling of different phases.

In order to test the possible effect of powder-liquid interaction force on flow behaviour, a presumed powder-liquid interaction force was proposed by the following equation with similarity to the powder-solid interaction force because the discrete liquid droplets have particle characteristics:

$$
\mathbf{F}_{f}^{l}=-\frac{1}{2 d_{l}} \rho_{f} \varepsilon_{f d}\left|\mathbf{u}_{f}-\mathbf{u}_{l}\right| f_{l}\left(\mathbf{u}_{f}-\mathbf{u}_{l}\right),
$$

where $f_{1}$ is treated as a function of liquid Froude number $f_{l}=14.98 / F_{l}^{1.33}$. A sensitivity analysis has been performed by changing the magnitude of a presumed interaction force in the modelling system. Figure 17 shows its effect on the dynamic powder holdup distribution. The dynamic powder holdup in the lower part of BF increases by about $10 \%$ when $F_{f}^{l}$ is considered in the simulation. Moreover, the magnitude of dynamic powder holdup increases with increasing $F_{f}^{l}$. On the other hand, it is also noted that the powder flow pattern has not been affected much by $F_{f}^{l}$, which explains why reasonable results can still be obtained even the liquid-powder interaction force was ignored in other studies. ${ }^{38,134)}$

Recently, attempts have also been made to model the gas-liquid-solid flow in BF hearth, where the effects of coke free zone, ${ }^{85}$ natural convection and turbulent model $^{86,88)}$ are investigated. Mathematical models have also been extended to identify the interface between slag and hot metal, ${ }^{90)}$ and establish the interrelationships between operation parameter, hearth condition and drainage behaviour. ${ }^{91,92)}$

The work described in this section may offer various methods to study the multiphase flow in a BF. For example, the new flooding diagram can help identify local flooding and instability in BF flow. The inclusion of liquid-powder interaction force may lead to a more accurate prediction of four-fluid flow in a BF. Development of a comprehensive

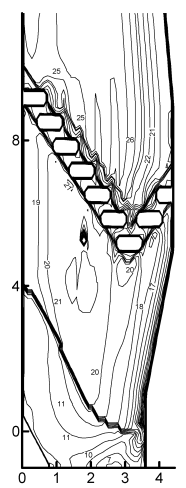

(a)

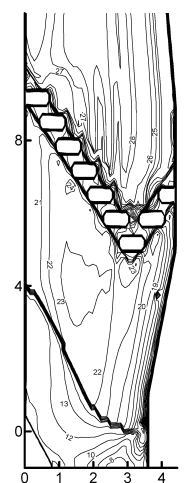

(b)

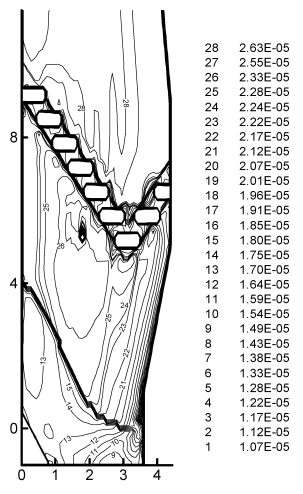

(c)
Fig. 17. Effect of $\mathbf{F}_{f}^{l}$ on the dynamic powder holdup ${ }^{128)}$ : (a) 0.5 $\mathbf{F}_{f}^{l}$; (b) $\mathbf{F}_{f}^{l}$; and (c) $1.5 \mathbf{F}_{f}^{l}$.

hearth model can help establish a better picture about the complicated multiphase flow and thermal-chemical behaviour which is still poorly understood. ${ }^{28)}$ However, it should be pointed out that the above results are all obtained under simplified conditions. They are largely preliminary when applied to the complicated BF operations. Continuous research in this area is therefore necessary in order to generate results useful to BF operation.

\section{Process Simulation}

Incorporated with heat transfer and chemical reaction models, a multiphase flow model can be used to provide detailed information about velocity, temperature and concentration distributions in a BF. This is important to understand the internal status and assess the BF performance under different operational conditions. Early applications of models have been extensively reviewed by Omori ${ }^{2}$ and Yagi. ${ }^{1)}$ Since the 1990 s, significant progress has been made in this area, mainly due to improved computational capability. These developments include: i) inclusion of more phases $^{38,134)}$ and more chemical species and chemical reactions ${ }^{135)}$ in the BF modelling; ii) development of models to take into account the dynamic and static holdups for liquid and powder phases ${ }^{108,126,136)}$; and iii) implementation of more comprehensive models, e.g. three-dimensional steady $^{137)}$ or transient ${ }^{26,138)}$ model.

The new models generate many new results which are useful to better understand the complicated phenomena in a BF. This can be demonstrated by the following examples related to four-fluid flow, ${ }^{38}$ transient $\mathrm{BF}$ internal conditions $^{26)}$ and identified specific operational index. ${ }^{126)}$ Figure 18 shows the flow fields for the four phases in a BF. ${ }^{38)}$ The location and shape of an assumed homogeneous cohesive zone can be identified based on temperature distribution and its existence clearly affects gas and powder flow direction. Solid particles flow as viscous fluid with an assumed solid stagnant zone. The liquid appears almost unaffected by gas flow, except for some deviation away from the bosh wall caused by the blast. These flow fields capture the macroscopic flow structure in a BF in spite of ignoring some microscopic phenomena such as the layer structure.

Change of operational conditions will change the internal 


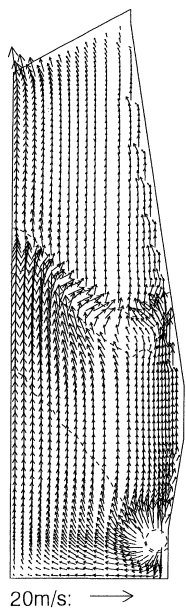

(a)

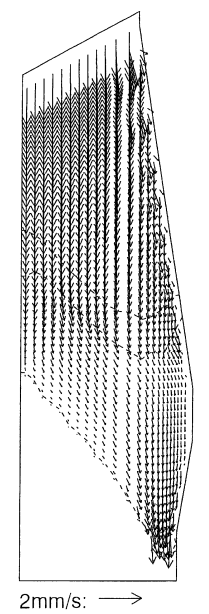

(b)

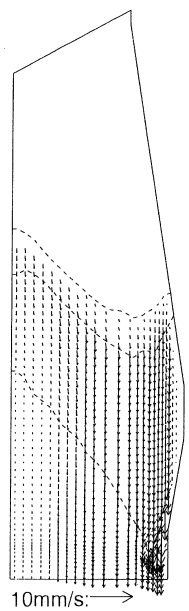

(c)

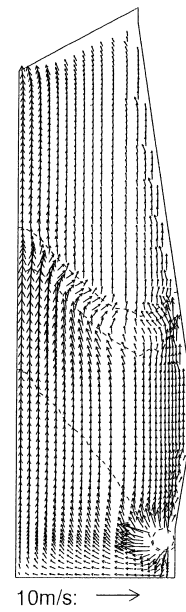

(d)
Fig. 18. Velocity vectors for (a) gas, (b) solid, (c) liquid and (d) powder phases. ${ }^{38)}$

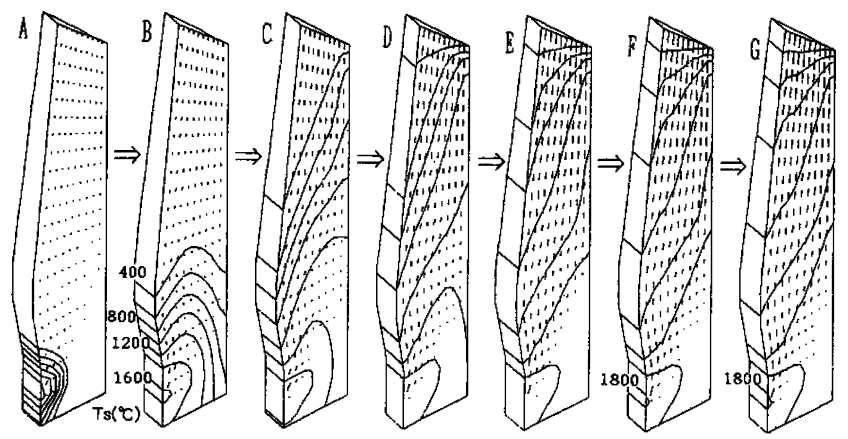

Fig. 19. Calculated solid temperature variation during blow-in operation. $^{26)}$

state in a BF. This transient process can be well described by a transient BF model. Figure 19 shows the simulated solid temperature fields during the blow-in process. ${ }^{26)}$ The model can also provide useful information such as hot metal and refractory temperatures, and gas utilization in a BF. Such information is useful to BF operators. Notably, efforts have also been made to examine the validity of such a BF model. This is usually made by comparing the predicted with measured results in terms of temperature field, production rates and top gas $\mathrm{CO}_{2}$ content. ${ }^{136)}$

In the lower part of $\mathrm{BF}$, the existence of liquid significantly increases the gas pressure gradient, possibly inducing unstable operation. Numerical simulation can provide information about liquid holdup, velocity, accumulation and flooding, as shown in Fig. 20. ${ }^{126)}$ These results demonstrate the effect of liquids on furnace behaviour as well as the capability of the response to changes in operating conditions such as bed permeability, furnace productivity and liquid physical properties. The combined information gives a so-called generated accumulation index which can be a valuable reference to the $\mathrm{BF}$ operator.

BF models offer a cost-effective method to assess the development of new technologies and improve process productivity and efficiency. ${ }^{26,109,134,139-145)}$ For example, in order to reduce carbon emission and improve the utilization of top gas, different top gas recycling methods can be used, such as simple replacement of normal blast gases with recycled top gas, oxygen enriched blast replacement, and hot re-

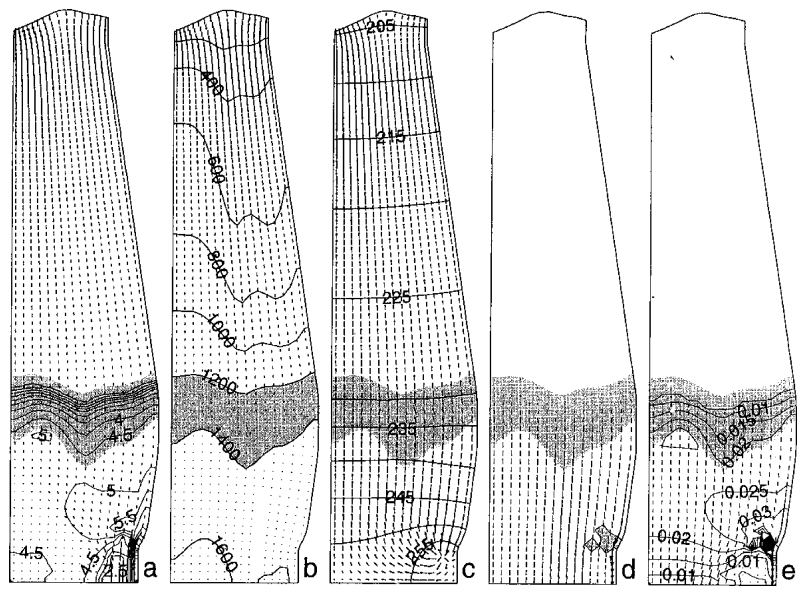

Fig. 20. Simulation results using the force balance model for liquid flow model in the BF simulation ${ }^{126}$ : (a) total liquid holdup; (b) solid temperature; (c) gas pressure; (d) flooding diagram; and (e) accumulation index.

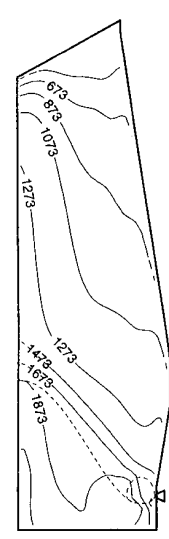

(a)

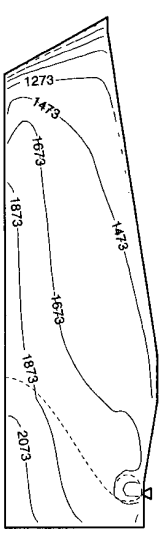

(b)

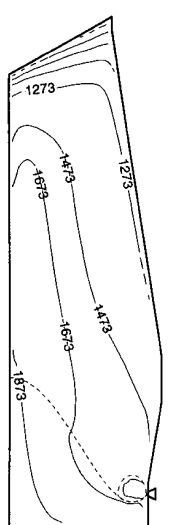

(c)

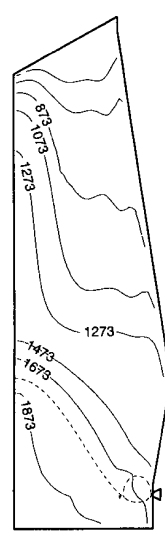

(d)
Fig. 21. Calculated solid temperature fields for different recycling methods ${ }^{139)}$ : (a) base; (b) simple; (c) $\mathrm{O}_{2}$ enriched; and (d) HRG.

ducing gas replacement (HGR) where $\mathrm{CO}_{2}$ has been removed from recycled top gas. ${ }^{139)}$ Some calculated solid temperature fields under different conditions are shown in Fig. 21. In the HRG case, because $\mathrm{CO}_{2}$ is stripped from the recycled gas, the temperature distribution suggests the furnace operates quite stably compared to other gas recycling methods. Together with the high $\mathrm{CO}$ and $\mathrm{H}_{2}$ partial pressures in the stack, in the HRG case, reduction is complete well before the solid enters the $\mathrm{CZ}$, thus the iron entering the $\mathrm{CZ}$ is probably sponge iron which is expected to melt quickly and easily over a narrow temperature range. Such findings are helpful in the decision-making for plant design and optimization, as discussed by Takatani ${ }^{27)}$ and Nogami. ${ }^{28)}$

\section{Concluding Remarks}

Multiphase flow in a BF involves multiscale phenomena that necessitate multiscale modelling. In the past decade or so, significant progress has been made in this direction, with various mathematical models proposed to address problems at different time and length scales. While the conventional continuum approach plays a dominant role in $\mathrm{BF}$ 
modelling, discrete approach becomes more and more important. Their combined usage offers a powerful tool for exploring the BF flow at both micro- and macro-scopic levels. Success has indeed been seen in the simulation and modelling of gas-solid, gas-powder, and gas-liquid flows, as reviewed in this article. On this basis, new models for BF four-fluid flow have also been developed. Their application indeed offers a cost-effective way to understand, control and optimize the complex BF process. Future research is certainly necessary in this area. In this connection, below just lists a few important challenges in BF multiphase flow research:

(1) Continuum and discrete approaches can both be used in the study of solid and/or powder flow in a BF. The two approaches have different advantages and disadvantages. For fundamental understanding, discrete approach is more suitable but for BF modelling, continuum approach is preferred. How to make best use of the two approaches is a challenging area. In theory, it is possible to link the discrete to continuum approach, which is a useful step to establish some constitutive relations for continuum-based process modelling. ${ }^{146,147)}$ This approach has not been tried yet in BF modelling. Moreover, there is a need to better understand the solid/powder flow in BF lower zone, e.g. raceway, deadman and hearth, which offers many research challenges such as the transition between stagnant and dynamic states, size/density segregation, possible powder accumulation, and so on. It is anticipated that the discrete approach will be very useful for such studies.

(2) The force balance approach, coupled with the stochastic approach, appears to be able to describe reasonably the flow of liquid phase which is microscopically discrete but macroscopically continuous. However, the approach as a whole is not complete. There is a need to formulate equations to generally quantify the parameters in the mathematical model, and to extend the approach to describe the different behaviour of liquid iron and slag, and their three dimensional flow in a BF. In this connection, there is also a need to quantify the interaction force between liquid iron and slag under different conditions; at present, this force was ignored in the continuum modelling. ${ }^{136)}$ It is also challenging to couple the liquid flow in the coke bed with the draining operation in the hearth.

(3) Steady-state four-fluid flow is possible, leading to various new concepts such as flooding diagrams for fourfluid system, and the quantification of liquid-powder interaction force. This development should be further exploited for BF application. In fact, to date, there are few experimental data and numerical analysis in the literature on fourfluid flow under BF conditions. There is a need for much more work to understand this complicated flow system.

(4) BF models have played a significant role in integrating the knowledge and offering information for process design and control. This role will be strengthened with the rapid development of computer technology and new modelling techniques. In this connection, continuous development and upgrading of a BF model is important and necessary. It is doubtless that development and application of reliable computer models can lead to long life campaigns, better operational control, decreased fuel consumption, improved productivity and reduced environmental impact in ironmaking. However, how to make best use of this technology in practice could be a challenging task for modern ironmakers.

\section{Nomenclature}

$a_{i j}$ : Effective contact area between phase $\mathrm{i}$ and $\mathrm{j}$ in unit volume of bed, $\mathrm{m}^{2} \cdot \mathrm{m}^{-3}$

$c$ : Damping coefficient

$C_{d}$ : Empirical coefficient for drag force

$c_{d 0}$ : Fluid drag coefficient on an isolated particle

$d$ : Diameter, $\mathrm{m}$

D : Stretching tensor

$D^{*}$ : Hydrodynamic equivalent diameter, $D^{*}=2 \phi_{s} d_{s}\left(1-\varepsilon_{s}\right) / 3 \varepsilon_{s}, \mathrm{~m}$

$\bar{D} ;$ Dimensionless diameter

$e$ : Coefficient of restitution

$E$ : Young's Modulus, $\mathrm{kg} \cdot \mathrm{m}^{-1} \cdot \mathrm{s}^{-2}$

$f$ : Empirical coefficient for drag force

F : Interaction force per unit volume, $\mathrm{kg} \cdot \mathrm{m}^{-2} \cdot \mathrm{s}^{-2}$

f: Inter-particle forces, $\mathrm{kg} \cdot \mathrm{m} \cdot \mathrm{s}^{-2}$

$F_{r}$ : Froude number: $\varepsilon_{s}\left|\mathbf{u}_{s}\right| /\left(d_{s} g\right)^{0.5}$ for solid phase; $\varepsilon_{f}\left|\mathbf{u}_{f}\right| /$ $\left(D^{*} g\right)^{0.5}$ for powder phase; $\varepsilon_{l}\left|\mathbf{u}_{l}\right|\left(D^{*} g\right)^{0.5}$ for liquid phase

$g$ : Magnitude of gravitational acceleration, equal to $9.81 \mathrm{~m} \cdot \mathrm{s}^{-2}$

g: Gravitational acceleration, $\mathrm{m} \cdot \mathrm{s}^{-2}$

$G$ : Gas flow rate, $\mathrm{kg} \cdot \mathrm{m}^{-2} \cdot \mathrm{s}^{-1}$

$G_{f}:$ Powder flow rate, $\mathrm{kg} \cdot \mathrm{m}^{-2} \cdot \mathrm{s}^{-1}$

$I$ : Moment of inertia of particle, $\mathrm{kg} \cdot \mathrm{m}^{2}$

I : Indentity tensor

$k_{i}$ : Number of particles in contact with particle $i$

$L: \quad$ Liquid flow rate, $\mathrm{kg} \cdot \mathrm{m}^{-2} \cdot \mathrm{s}^{-1}$

$m$ : Mass of particle, $\mathrm{kg}$

n: Unit outward normal vector

$n$ : Number of real particles in a computational cell

$N$ : Number of sampling particles in a computational cell

$p:$ Pressure, $\mathrm{Pa}$

$P$ : Powder flow rate, $\mathrm{kg} \cdot \mathrm{m}^{-2} \cdot \mathrm{s}^{-1}$

$P_{i j}:$ Collision probability

$P_{e}: \quad$ Effective pressure of solid phase, $\mathrm{Pa}$

$R e$ : Reynolds number: $R e_{i}=\phi_{i} \rho_{i} \varepsilon_{i}\left|\mathbf{u}_{i}\right| d_{s} / \mu_{i}$ for $i=g$ or $l$

$R$ : Radius of particle $i, \mathrm{~m}$

$\mathbf{R}$ : Vector from the mass centre of the particle to the contact point, $\mathrm{m}$

$S$ : Source term

$t$ : Time, $\mathrm{s}$

$\mathbf{T}$ : Torque, $\mathrm{kg} \cdot \mathrm{m}^{2} \cdot \mathrm{s}^{-2}$

u : Interstitial fluid velocity, $\mathrm{m} \cdot \mathrm{s}^{-1}$

$U_{s}$ : Stochastic velocity of liquid dispersion flow, $\mathrm{m} \cdot \mathrm{s}^{-1}$

$U_{s 0}$ : Maximum stochastic velocity of liquid dispersion flow, $\mathrm{m} \cdot \mathrm{s}^{-1}$

$U:$ Superficial velocity, $\mathrm{m} \cdot \mathrm{s}^{-1}$

$\mathbf{U}$ : Superficial velocity vector, $\mathrm{m} \cdot \mathrm{s}^{-1}$

v: Particle translational velocity, $\mathrm{m} \cdot \mathrm{s}^{-1}$

$V_{0}$ : Dimensionless volume of a computational cell

Greek

$\delta$ : Displacement between two contacting particles, $\mathrm{m}$

$\boldsymbol{\delta}_{t}$ : Tangential displacement vector, $\mathrm{m}$ 
$\delta_{t, \text { max }}: \quad$ Maximum tangential displacement, $\mathrm{m}$

$\chi$ : Empirical coefficient

$\varepsilon$ : Volume fraction, $\mathrm{m}^{3} \cdot \mathrm{m}^{-3}$

$\varepsilon_{v}: \quad$ Voidage of packed bed, $\mathrm{m}^{3} \cdot \mathrm{m}^{-3}$

$v$ : Poisson ratio

$\phi:$ Shape factor $(-)$

$\dot{\gamma}$ : Shear rate, $\mathrm{s}^{-1}$

$\eta$ : Coefficient of plastic modulus

$\mu$ : Viscosity, $\mathrm{kg} \cdot \mathrm{m}^{-1} \cdot \mathrm{s}^{-1}$

$\mu_{0}$ : Yield viscosity, $\mathrm{kg} \cdot \mathrm{m}^{-1} \cdot \mathrm{s}^{-1}$

$\mu_{r}$ : Rolling friction coefficient, $\mathrm{m}$

$\mu_{s f}$ : Sliding friction coefficient

$\rho$ : Density, $\mathrm{kg} \cdot \mathrm{m}^{-3}$

$\omega:$ Particle angular velocity, $\mathrm{s}^{-1}$

$\tau$ : Shear stress, $\mathrm{Pa}$

$\tau_{0}: \quad$ Yield stress, $\mathrm{Pa}$

$\tau$ : Stress tensor, $\mathrm{Pa}$

Subscripts

$\begin{array}{ll}c: & \text { Contact } \\ d: & \text { Damping } \\ g: & \text { Gas } \\ f: & \text { Fine powder }\end{array}$

$f d$ : Dynamic powder holdup

$f l$ : Fluid

$i$ : Identifier (g, f, s or 1) in Eqs. (1) and (2)

$i$ : $\quad$ Particle $i$

$i j$ : $\quad$ between particles $i$ and $j$

$j:$ Particle $j$

$l$ : Liquid

$n$ : Normal component

$p$ : Particle

$r$ : Rolling friction

$r d$ : Rate dependent

$r i$ : Rate independent

$s$ : Solid

$t$ : Tangential component

$w$ : Water

Superscripts

$\begin{array}{ll}A: & \text { Model A } \\ B: & \text { Model B } \\ g: & \text { Gas } \\ f: & \text { Powder } \\ j: & \text { Identifier }(\mathrm{g}, \mathrm{f}, \mathrm{s} \text { or } \mathrm{l}) \\ l: & \text { Liquid } \\ s: & \text { Solid }\end{array}$

\section{REFERENCES}

1) J. Yagi: ISIJ Int., 33 (1993), 619.

2) Y. Omori: Blast Furnace Phenomena and Modelling, Elsevier Applied Science, London, (1987), 41.

3) M. Hatano and K. Kurita: Tetsu-to-Hagané, 66 (1980), 1898.

4) T. Sugiyama and M. Sugata: Nippon Steel Technical Report No. 35, (1987), 32.

5) R. M. Nedderman and U. Tüzün: Powder Technol., 22 (1979), 243.

6) H. Takahashi, K. Kushima and T. Takeuchi: ISIJ Int., 29 (1989), 117.

7) S. Huang, Z. Wang and Y. Jin: Chem. Eng. Sci., 54 (1999), 2067.

8) K. Shibata, M. Shimizu, S. Inaba, R. Takahashi and J. Yagi: ISIJ Int., 31 (1991), 434.

9) X. Song, Z. Wang, Y. Jin and Z. Tanaka: Powder Technol., 83 (1995), 127.
10) A. G. J. Van der ham, W. Prins and W. P. M. Van Swaaij: AIChE Symp. Ser, 89 (1993), 53.

11) H. Yamaoka: Tetsu-to-Hagané, 72 (1986), 2194.

12) K. Shibata, M. Shimizu, S. Inaba, R. Takahashi and J. Yagi: Tetsuto-Hagané, 77 (1991), 1267.

13) Y. Ohno and M. Schneider: Tetsu-to-Hagané, 74 (1988), 1923.

14) J. Wang, R. Takahashi and J. Yagi: Tetsu-to-Hagané, 77 (1991), 1585 .

15) J. Szekely and Y. Kajiwara: Trans. Iron Steel Inst. Jpn., 19 (1979), 76.

16) G. X. Wang, S. J. Chew, A. B. Yu and P. Zulli: Metall. Mater. Trans. $B, 28 B$ (1997), 333.

17) G. X. Wang, S. J. Chew, A. B. Yu and P. Zulli: ISIJ Int., 37 (1997), 573.

$18)$ B. H. Xu, A. B. Yu, S. J. Chew and P. Zulli: Powder Technol., 109 (2000), 13.

19) Y. Q. Feng, D. Pinson, A. B. Yu, S. J. Chew and P. Zulli: Steel Res., 74 (2003), 523.

20) H. Nogami, H. Yamaoka and K. Takatani: ISIJ Int., 44 (2004), 2150 .

21) S. Yuu, T. Umekage and T. Miyahara: ISIJ Int., 45 (2005), 1406.

22) T. Nouchi, A. B. Yu and K. Takeda: Powder Technol., 134 (2003), 98.

23) H. Yamaoka: ISIJ Int., 31 (1991), 939.

24) X. F. Dong, D. Pinson, S. J. Zhang, A. B. Yu and P. Zulli: Powder Technol., 149 (2004), 1.

25) S. J. Chew, G. X. Wang, A. B. Yu and P. Zulli: Ironmaking Steelmaking, 24 (1997), 392.

26) K. Takatani, T. Inada and Y. Ujisawa: ISIJ Int., 39 (1999), 15.

27) K. Takatani: Tetsu-to-Hagané, 81 (1995), 1031.

28) H. Nogami: Tetsu-to-Hagané, 89 (2003), 211.

29) R. Jackson: Trans. Inst. Chem. Eng., 41 (1963), 13.

30) S. L. Soo: Multiphase Fluid Dynamics, Science Press, Beijing, (1990), 303.

31) D. Gidaspow: Multiphase Flow and Fluidization, Academic Press, San Diego, (1994), 31.

32) Y. Q. Feng and A. B. Yu: Ind. Eng. Chem. Res., 43 (2004), 8378.

33) P. G. de Gennes: Rev. Mod. Phys., 71 (1999), S374.

34) S. J. Zhang, A. B. Yu, P. Zulli, B. Wright and U. Tüzün: ISIJ Int., 38 (1998), 1311.

35) H. Aoki, H. Nogami, H. Tsuge, T. Miura and T. Furukawa: ISIJ Int., 33 (1993), 646.

36) S. S. Mondal, S. K. Som and S. K. Dash: J. Phys. D: Appl. Phys., 38 (2005), 1301.

37) J. Chen, T. Akiyama, H. Nogami, J. Yagi and H. Takahashi: ISIJ Int., 33 (1993), 664.

38) P. R. Austin, H. Nogami and J. Yagi: ISIJ Int., 37 (1997), 458.

39) I. Iliuta, P. A. Grandjean, S. Piche and F. Larachi: Chem. Eng. Sci., 58 (2003), 1373.

40) J. Chen, T. Akiyama, H. Nogami and J. Yagi: ISIJ Int., 34 (1994), 133.

41) X. F. Dong, S. J. Zhang, D. Pinson, A. B. Yu and P. Zulli: Powder Technol., 149 (2004), 10.

42) S. Q. Li, Y. L. Ding, D. S. Wen and Y. R. He: Chem. Eng. Sci., 61 (2006), 1922.

43) L. D. Chen: Ph.D. thesis, University of New South Wales, Sydney, Australia, (2006).

44) P. A. Cundall and O. D. L. Strack: Geotechnique, 29 (1979), 47.

45) P. A. Langston, U. Tüzün and D. M. Heyes: Powder Technol., 85 (1995),

46) T. Tanaka, M. Nishida, T. Kunimochi and T. Takagi: Powder Technol., 124 (2002), 160.

47) H. P. Zhu and A. B. Yu: Physica A, 325 (2003), 347.

48) R. Y. Yang, R. P. Zou and A. B. Yu: Phys. Rev. E, 62 (2000), 3900.

49) R. Y. Yang, R. P. Zou and A. B. Yu: AIChE J., 49 (2003), 1656.

50) T. Nouchi, K. Takeda and A. B. Yu: ISIJ Int., 43 (2003), 187.

$51)$ B. H. Xu and A. B. Yu: Chem. Eng. Sci., 52 (1997), 2785.

52) S. I. Rubinow and J. B. Keller: J. Fluid Mech., 11 (1961), 447.

53) P. G. Saffman: J. Fluid Mech., 22 (1965), 385.

54) F. Odar: J. Fluid Mech., 25 (1966), 591.

55) F. Odar and W. S. Hamilton: J. Fluid Mech., 18 (1964), 302.

56) P. R. Schöneborn: Int. J. Multiph. Flow, 2 (1975), 307.

57) Z. Y. Zhou, H. P. Zhu, A. B. Yu, B. Wright, D. Pinson and P. Zulli: 
ISIJ Int., 45 (2005), 1828.

58) Y. Tsuji, T. Kawaguchi and T. Tanaka: Powder Technol., 77 (1993), 79.

59) A. B. Yu and B. H. Xu: J. Chem. Technol. Biotechnol., 78 (2003), 111.

60) B. H. Xu, Y. Q. Feng, A. B. Yu, S. J. Chew and P. Zulli: Powder Handl. Process., 13 (2001), 71.

61) H. Takahashi and N. Komatsu: ISIJ Int., 33 (1993), 655.

62) H. Takahashi, M. Tanno and J. Katayama: ISIJ Int., 36 (1996), 1354

63) M. Ichida, M. Takao, K. Kunitomo, S. Matsuzaki, T. Deno and K. Nishihara: ISIJ Int., 36 (1996), 493.

64) J. Jimenez, J. Mochon, A. Formoso and J. S. de Ayala: ISIJ Int., 40 (2000), 114.

65) Y. Kajiwara, T. Inada, T. Tanaka and T. Jimbo: Sumitomo Search, 44 (1990), 249.

66) Y. Kajiwara, T. Jimbo, T. Joko, Y. Aminaga and T. Inada: Trans Iron Steel Inst. Jpn., 24 (1984), 799.

67) C. K. Ho, Y. M. Chen, C. I. Lin and J. R. Jeng: Powder Technol., 63 (1990), 13.

68) T. Inada, Y. Matsukura, M. Yaeda, S. Matsumura, S. Komatsu, T. Yamamoto and M. Onishi: ISIJ Int., 43 (2003), 1376.

69) S. J. Zhang, A. B. Yu, P. Zulli, B. Wright and P. Austin: Appl. Math. Model., 26 (2002), 141.

70) H. Nogami and J. Yagi: ISIJ Int., 44 (2004), 1826.

$71)$ S. A. Zaïmi, T. Akiyama, J. B. Guillot and J. Yagi: ISIJ Int., 40 (2000), 322

72) S. A. Zaïmi, J. B. Guillot and H. Biausser: Ironmaking Steelmaking, 30 (2003), 475

73) T. Tanaka, Y. Kajiwara and T. Inada: Trans. Iron Steel Inst. Jpn., 28 (1988), 907.

74) U. Tüzün, G. T. Houlsby, R. M. Nedderman and S. B. Savage: Chem. Eng. Sci., 37 (1982), 1691.

75) Y. Kajiwara, T. Inada and T. Tanaka: Trans. Iron Steel Inst. Jpn., 28 (1988), 916

76) J. M. Burgess: Prog. Energy Combust. Sci., 11 (1985), 61.

77) P. J. Flint and J. M. Burgess: Metall. Trans. B, 23B (1992), 267.

$78)$ G. S. S. R. K. Sastry, G. S. Gupta and A. K. Lahiri: ISIJ Int., 43 (2003), 153

79) S. Rajneesh, S. Sarkar and G. S. Gupta: ISIJ Int., 44 (2004), 1298.

80) G. S. Gupta, S. Rajneesh, V. R. Rudolph, V. Singh, S. Sarkar and J. Litster: Metall. Mater. Trans. B, 36B (2005), 755.

81) D. Desai: Trans. Iron Steel Soc., 14 (1993), 45.

82) R. J. Nightingale and F. W. B. U. Tanzil: Iron Steelmaker, 24 (1997), 35.

83) A. Preuer, J. Winter and H. Hiebler: Steel Res., 63 (1992), 139.

84) J. Brännbacka and H. Saxén: ISIJ Int., 43 (2003), 1519.

85) K. Takatani, T. Inada and K. Takata: ISIJ Int., 41 (2001), 1139.

86) V. Panjkovic, J. S. Truelove and P. Zulli: Ironmaking Steelmaking, 29 (2002), 390

87) C. Q. Zhou, F. Yan, D. Roldan, D. Huang, P. Chaubal and Y. Zhao: Proc. of the Iron \& Steel Technol. Conf., United States, (2005), 283.

$88)$ W. T. Cheng, C. N. Huang and S. W. Du: Chem. Eng. Sci., 60 (2005), 4485.

89) M. G. Zhao, T. L. Sun, S. S. Cheng and Z. K. Gao: J. Iron Steel Res. Int., 12 (2005), 5.

90) K. Nishioka, T. Maeda and M. Shimizu: ISIJ Int., 45 (2005), 669.

91) K. Nishioka, T. Maeda and M. Shimizu: ISIJ Int., 45 (2005), 1496.

92) K. Nishioka, T. Maeda and M. Shimizu: ISIJ Int., 45 (2005), 1506.

93) H. Kawai and H. Takahashi: ISIJ Int., 44 (2004), 1140.

94) H. Nogami, K. Toda, S. Pintowantoro and J. Yagi: ISIJ Int., 44 (2004), 2127.

95) H. Takahashi, H. Kawai, M. Kobayashi and T. Fuku: ISIJ Int., 45 (2005), 1386.

96) H. Nogami, P. R. Austin, J. Yagi and K. Yamaguchi: ISIJ Int., 44 (2004), 500.

97) H. Yamaoka: Tetsu-to-Hagané, 72 (1986), 403.

98) K. Kusakabe, T. Yamaki and S. Morooka: Tetsu-to-Hagané, 77 (1991), 1407.

99) K. Kusakabe, T. Yamaki and S. Morooka: Tetsu-to-Hagané, 77 (1991), 1413.
100) N. Hidaka, J. Iyama, T. Matsumoto, K. Kusakabe and S. Morooka: Powder Technol., 95 (1998), 265.

101) N. Hidaka, T. Matsumoto, K. Kusakabe and S. Morooka: J. Chem. Eng. Jpn., 32 (1999), 197.

102) N. Hidaka, T. Matsumoto, K. Kusakabe and S. Morooka: J. Chem. Eng. Jpn., 33 (2000), 152.

103) Y. L. Ding, Z. L. Wang, D. S. Wen, M. Ghadiri, X. F. Fan and D. Parker: Chem. Eng. Sci., 60 (2005), 5231.

104) H. Nogami, M. Takatoku and J. Yagi: ISIJ Int., 44 (2004), 2144.

105) K. Takeda and F. C. Lockwood: ISIJ Int., 37 (1997), 432.

106) T. Umekage, S. Yuu and M. Kadowaki: ISIJ Int., 45 (2005), 1416.

107) T. Sugiyama: Tetsu-to-Hagané, 82 (1996), 29.

108) S. Pintowantoro, H. Nogami and J. Yagi: ISIJ Int., 44 (2004), 304.

109) H. Nogami, S. Pintowantoro and J. Yagi: ISIJ Int., 45 (2005), 1489.

110) K. Takeda and F. C. Lockwood: Tetsu-to-Hagané, 82 (1996), 492.

111) L. S. Fan, M. Toda and S. Satija: Powder Technol., 36 (1983), 107.

112) C. Yamagata, S. Suyama, S. Horisaka, K. Takatani, Y. Kajiwara, S. Komatsu, H. Shibuta and Y. Aminaga: ISIJ Int., 32 (1992), 725.

113) M. Avila Ribas, H. Nogami, R. Takahashi and J. Yagi: ISIJ Int., 45 (2005), 303.

114) X. F. Dong, D. Pinson, S. J. Zhang, A. B. Yu and P. Zulli: Appl. Math. Model., 30 (2006), 1293.

115) G. S. Gupta, J. D. Litster, V. R. Rudolph, E. T. White and A. Domanti: ISIJ Int., 36 (1996), 32.

116) H. Kawabata, Z. G. Liu, F. Fujita and T. Usui: ISIJ Int., 45 (2005), 1466.

117) M. Niu, T. Akiyama, R. Takahashi and J. Yagi: AIChE J., 42 (1996), 1181.

118) M. Li, Y. Bando, R. Tanigawara, T. Tsuge, K. Yasuda and M. Nakamura: J. Chem. Eng. Jpn., 34 (2001), 948.

119) Y. Bando, S. Hayashi, A. Matsubara and M. Nakamura: ISIJ Int., 45 (2005), 1461.

120) W. M. Husslage, M. A. Reuter, R. H. Heerema, T. Bakker and A. G. S. Steeghs: Metall. Mater. Trans. B, 36B (2005), 765.

121) Y. Eto, K. Takeda, S. Miyagawa, S. Taguchi and H. Itaya: ISIJ Int., 33 (1993), 681.

122) S. J. Chew, P. Zulli and A. B. Yu: ISIJ Int., 41 (2001), 1112.

123) D. Y. Liu, G. X. Wang and J. D. Litster: AIChE J., 48 (2002), 953.

124) D. Y. Liu, S. Wijeratne and J. D. Litster: Scand. J. Metall., 26 (1997), 79.

125) G. X. Wang, J. Litster and A. B. Yu: ISIJ Int., 40 (2000), 627.

126) S. J. Chew, P. Zulli and A. B. Yu: ISIJ Int., 41 (2001), 1122.

127) X. F. Dong, A. B. Yu and P. Zulli: Flooding Analysis of Multi-phase Flow in a Moving Bed, Internal Report, (2006).

128) X. F. Dong, A. B. Yu, J. Burgess, D. Pinson, S. Chew and P. Zulli: 5th Int. Symp. on Multiphase Flow, Heat Mass Transfer and Energy Conversion, China, (2005), (CD Rom Edition).

129) Perry's Chemical Engineering's Handbook, 7th ed., McGraw-Hill, New York, (1997), 14.

130) R. F. Strigle: Packed Tower Design and Applications, Gulf Publ. Co., Houston, (1994), 1.

131) T. Fukutake and V. Rajakumar: ISIJ Int., 22 (1982), 355.

132) T. Pham, D. Pinson, A. B. Yu and P. Zulli: Chem. Eng. Sci., 54 (1999), 5339.

133) D. Pinson, T. Pham, A. B. Yu and P. Zulli: Steel Res., 75 (2004), 106.

134) J. Castro, H. Nogami and J. Yagi: ISIJ Int., 40 (2000), 637.

135) P. R. Austin, H. Nogami and J. Yagi: ISIJ Int., 37 (1997), 748.

136) P. R. Austin, H. Nogami and J. Yagi: ISIJ Int., 38 (1998), 246.

137) J. Castro, H. Nogami and J. Yagi: ISIJ Int., 42 (2002), 44.

138) K. Takatani, T. Inada and Y. Ujisawa: CAMP-ISIJ, 7 (1994), 50.

139) P. R. Austin, H. Nogami and J. Yagi: ISIJ Int., 38 (1998), 239

140) P. R. Austin, H. Nogami and J. Yagi: ISIJ Int., 38 (1998), 697.

141) M. S. Chu, H. Nogami and J. Yagi: ISIJ Int., 44 (2004), 510.

142) T. Sato, T. Nouchi and M. Kiguchi: Kawasaki Steel Tech. Rep., 38 (1998), 24.

143) J. Castro, H. Nogami and J. Yagi: ISIJ Int., 41 (2001), 18.

144) M. S. Chu, H. Nogami and J. Yagi: ISIJ Int., 44 (2004), 801.

145) J. Castro, H. Nogami and J. Yagi: ISIJ Int., 42 (2002), 1203.

146) H. P. Zhu and A. B. Yu: Phys. Rev. E, 66 (2002), 021302.

147) A. B. Yu: Eng. Comput., 21 (2004), 205. 